ARTICLE OPEN

\title{
Immunisation of two rodent species with new live-attenuated mutants of Yersinia pestis CO92 induces protective long-term humoral- and cell-mediated immunity against pneumonic
} plague

\author{
Bethany L Tiner ${ }^{1}$, Jian Sha ${ }^{1,2}$, Yingzi Cong ${ }^{1,2,3,4,5}$, Michelle L Kirtley ${ }^{1}$, Jourdan A Andersson ${ }^{1}$ and Ashok K Chopra ${ }^{1,2,4,5}$
}

We showed recently that the live-attenuated $\Delta l p p \Delta m s b B \Delta$ ail and $\Delta l p p \Delta m s b B:: a i l L 2$ mutants of Yersinia pestis CO92 provided shortterm protection to mice against developing subsequent lethal pneumonic plague. These mutants were either deleted for genes encoding Braun lipoprotein (Lpp), an acetyltransferase (MsbB) and the attachment invasion locus (Ail) ( $\Delta / p p \Delta m s b B \Delta a i l)$ or contained a modified version of the ail gene with diminished virulence ( $\Delta / p p \Delta m s b B:: a i l L 2)$. Here, long-term immune responses were first examined after intramuscular immunisation of mice with the above-mentioned mutants, as well as the newly constructed $\Delta l p p \Delta m s b B \Delta$ pla mutant, deleted for the plasminogen-activator protease (pla) gene instead of ail. Y. pestis-specific lgG levels peaked between day 35 and 56 in the mutant-immunised mice and were sustained until the last tested day 112 . Splenic memory B cells peaked earlier (day 42) before declining in the $\Delta l p p \Delta m s b B:: a i l L 2$ mutant-immunised mice while being sustained for 63 days in the $\Delta / p p \Delta m s b B \Delta$ ail and $\Delta l p p \Delta m s b B \Delta p l a$ mutant-immunised mice. Splenic $C D 4^{+} \mathrm{T}$ cells increased in all immunised mice by day 42 with differential cytokine production among the immunised groups. On day 120, immunised mice were exposed intranasally to wild-type (WT) CO92, and 80-100\% survived pneumonic challenge. Mice immunised with the above-mentioned three mutants had increased innate as well as $\mathrm{CD} 4^{+}$responses immediately after WT CO92 exposure, and coupled with sustained antibody production, indicated the role of both arms of the immune response in protection. Likewise, rats vaccinated with either $\Delta l p p \Delta m s b B \Delta a i l$ or the $\triangle l p p \triangle m s b B \Delta p l a$ mutant also developed long-term humoral and cell-mediated immune responses to provide $100 \%$ protection against developing pneumonic plague. On the basis of the attenuated phenotype, the $\Delta l p p \Delta m s b B \Delta a i l$ mutant was recently excluded from the Centers for Disease Control and Prevention select agent list.

Npj Vaccines (2016) 1, 16020; doi:10.1038/npjvaccines.2016.20; published online 13 October 2016

\section{INTRODUCTION}

There has been a rise in the number of human plague cases globally resulting in the categorisation of Yersinia pestis, the aetiological agent of the highly fatal pneumonic plague, as a reemerging pathogen by the World Health Organization. ${ }^{1}$ The progression of pneumonic plague is very rapid after first appearance of the symptoms in humans, and the case fatality rate approaches $100 \%$, if the antimicrobial treatment is delayed. ${ }^{2-4}$ Unfortunately, antibiotic-resistant $Y$. pestis strains have been isolated from plague patients and/or engineered for bioweaponization, ${ }^{4}$ which is concerning as $Y$. pestis is classified by the Centers for Disease Control and Prevention (CDC) as a Tier1 select agent. ${ }^{4}$ The optimal strategy for protection against this deadly disease would be through vaccination; however, there are currently no Food and Drug Administration (FDA)-licensed plague vaccines available in the United States. ${ }^{5-7}$

Live-attenuated vaccines promote both humoral- and cellmediated immune responses making them the optimal option to protect humans against pneumonic plague. ${ }^{5,8}$ The various live- attenuated $Y$. pestis EV76 vaccine strains, which lack the pigmentation locus (pgm) required for iron acquisition, have been used in plague endemic parts of the world due to vaccine strains' ability to provide protection against both bubonic and pneumonic plague. ${ }^{5}$ Unfortunately, these EV76-based vaccines are not FDA approved because of high reactogenicity and these strains are not genetically uniform. ${ }^{9}$ In addition, $\Delta p g m$ mutants of $Y$. pestis cause fatal infection in individuals with diseases such as hemochromatosis. ${ }^{10,11}$

Subunit plague vaccines, mainly composed of two immunogens, namely F1 capsular antigen and a type III secretion system component and effector low calcium response $\mathrm{V}$ antigen (LcrV), are generally protective across various animal species ${ }^{5,8,12-18}$ but such vaccines largely generate a humoral immune response. Furthermore, F1-LcrV-based vaccines would not be ideal against infection with $Y$. pestis strains devoid of capsule or those harbouring variants of LcrV with diverged amino acid sequences. $^{19-22}$

Therefore, our recent efforts to develop novel live-attenuated vaccines led to the deletion and/or modification of the genes

\footnotetext{
${ }^{1}$ Department of Microbiology and Immunology, University of Texas Medical Branch, Galveston, TX, USA; ${ }^{2}$ Institute for Human Infections and Immunity, University of Texas Medical Branch, Galveston, TX, USA; ${ }^{3}$ Department of Pathology, University of Texas Medical Branch, Galveston, TX, USA; ${ }^{4}$ Sealy Center for Vaccine Development and World Health Organization Collaborating Center for Vaccine Research, University of Texas Medical Branch, Galveston, TX, USA and ${ }^{5}$ Center for Biodefense and Emerging Infectious Diseases, University of Texas Medical Branch, Galveston, TX, USA.
}

Correspondence: J Sha (jisha@utmb.edu) or AK Chopra (achopra@utmb.edu)

Received 13 May 2016; revised 29 July 2016; accepted 22 August 2016 
encoding Braun lipoprotein (Lpp), an acetyltransferase (MsbB), the attachment invasion locus (Ail) and the plasminogen-activator protease (Pla). ${ }^{23-26}$ Lpp activates toll-like receptor (TLR)-2 leading to pro-inflammatory cytokine production and septic shock. ${ }^{27-30}$ MsbB modifies lipopolysaccharide (LPS) resulting in its increased biological potency. ${ }^{26,31-35}$ Ail is an outer membrane protein with extracellular loop 2 (L2) reported to be responsible for Ailmediated bacterial serum resistance and adherence/invasion to the host cells. ${ }^{25,36-43}$ Pla facilitates bacterial dissemination during bubonic and pneumonic plague as well as contributes to intracellular survival of $Y$. pestis in macrophages. ${ }^{24,44}$

Recently, our laboratory generated three live-attenuated mutant strains of $Y$. pestis CO92. The $\Delta l p p \Delta m s b B \Delta$ ail triple mutant was shown to be safe and highly immunogenic. ${ }^{23,25}$ However, as Ail also has immunogenic potential, ${ }^{45}$ the corresponding virulence-associated amino acid residues in L2 of the ail gene were mutated generating the $\Delta l p p \Delta m s b B$ ::aill2 mutant of CO92. ${ }^{25}$ Immunisation of mice with two doses of either $\Delta / p p$ $\Delta m s b B \Delta$ ail or the $\Delta l p p \Delta m s b B:: a i l L 2$ mutant via the intramuscular (i.m.) route triggered robust humoral and cellular immune responses. Such vaccinated mice were $100 \%$ protected when challenged 21 days after the second immunisation with high pneumonic challenge doses (70-92 LD $_{50}$ ) of wild-type (WT) CO92, indicating these vaccines were capable of providing short-term protection. ${ }^{25}$ We also developed a $\Delta l p p \Delta p l a$ double mutant of CO92, and mice immunised with this double mutant developed protective immunity against subsequent pneumonic challenge. ${ }^{24}$ Studies have shown that deletion of the $m s b B$ gene from $Y$. pestis EV76 strain modulated major immunoreactive antigens, ${ }^{46}$ and that the $\Delta l p p \Delta m s b B$ double mutant was significantly more attenuated compared with the single mutants. ${ }^{26}$ Therefore, we deleted $m s b B$ gene from the $\Delta l p p \Delta p l a$ double mutant to improve immunogenicity and safety of the $\Delta l p p \Delta m s b B \Delta p l a$ triple mutant.

It is imperative that a successful plague vaccine should generate long-term immunity in immunised animals. Thus, it is essential to examine if the newly created $\Delta l p p \Delta m s b B \Delta p l a$ mutant as well as the $\Delta l p p \Delta m s b B \quad \Delta$ ail and $\Delta l p p \Delta m s b B:: a i l L 2$ mutants have the ability to elicit protective long-term humoral- and cell-mediated immune responses, which formed the basis of this study. To authenticate our data, we used both mouse and rat models of pneumonic plague.

\section{RESULTS}

Attenuation in virulence of the newly generated $\Delta l p p \Delta m s b B \Delta p l a$ mutant of $Y$. pestis $\mathrm{CO} 2$

To gauge the extent of attenuation, mice ( $n=5$ per group) were infected by the intranasal (i.n.) route with $2.5 \times 10^{6}$ colony forming units (CFU) or $5 \times 10^{6}$ CFU doses of the WT CO92 or the $\Delta / p p$ $\triangle m s b B \Delta$ pla mutant (representing 5,000 and $10,000 \mathrm{LD}_{50}$ of the WT bacterium). ${ }^{24}$ Although mice inoculated with the WT CO92 died by day 3 post infection (p.i.), all mice infected with the $\Delta / p p$ $\triangle m s b B \Delta p l a$ mutant survived with no clinical signs of the disease such as ruffled fur, hunch back and lethargy (Figure 1). On day 22, the surviving mice as well as the age-matched naive controls were exposed i.n. to $1.8 \times 10^{4}$ CFU dose of WT CO92 (36 LD 50$)$. All of the naive mice succumbed to infection by day 27 ( 5 days p.i.). Animals receiving the higher immunisation dose of the $\Delta l p p \Delta m s b B \Delta p l a$ mutant had $80 \%$ survival after WT CO92 infection; although dropping to $70 \%$ at the lower vaccination dose (Figure 1).

Evaluation of long-term humoral immunity in mice after immunisation with live-attenuated mutants of $Y$. pestis CO92

To further gauge vaccine potential of these three mutants (i.e. $\Delta l p p \Delta m s b B \Delta$ ail, $\Delta l p p \Delta m s b B::$ aill 2 and $\Delta l p p \Delta m s b B \Delta p l a)$, we used the optimal vaccination regimen, ${ }^{25}$ which utilised two i.m. doses $\left(2.5 \times 10^{6}\right.$ CFU/dose, 21 days apart). A recent study also indicated

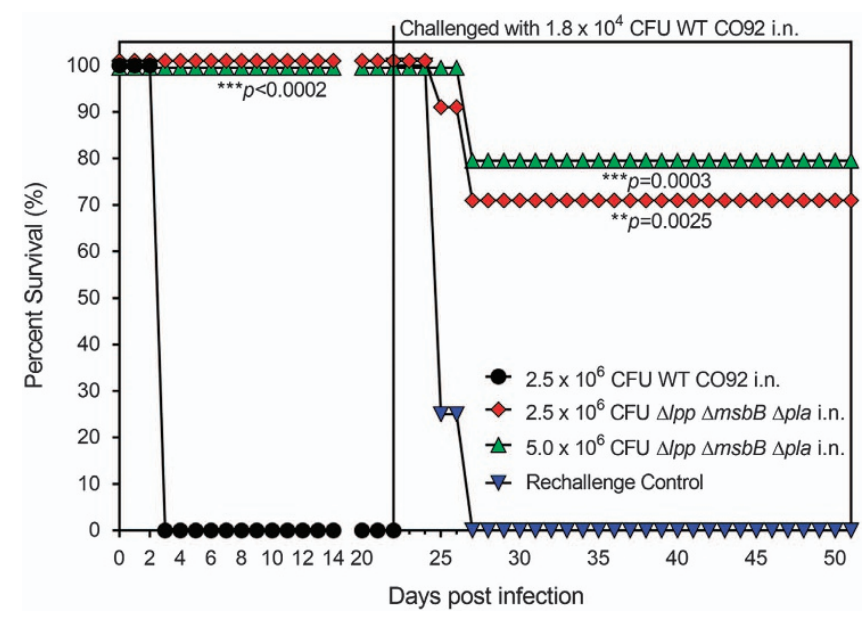

Figure 1. Survival analysis and protection conferred by vaccination of mice with high doses of the $\Delta l p p \Delta m s b B \Delta$ pla mutant of $Y$. pestis CO92 in a pneumonic plague mouse model. Female Swiss-Webster mice ( $n=5$ per group) were exposed by the i.n. route with one dose of $2.5 \times 10^{6} \mathrm{CFU}$ or $5 \times 10^{6} \mathrm{CFU}$ of the $\Delta / p p \Delta m s b B \Delta$ pla mutant on day 0 . Mice infected with the $2.5 \times 10^{6}$ CFU of WT CO92 luc2 served as a control. Surviving mice were then rechallenged i.n. on day 22 with $1.8 \times 10^{4} \mathrm{CFU}\left(36 \mathrm{LD}_{50} ; 1 \mathrm{LD}_{50} \cong 500 \mathrm{CFU}\right)$ of WT CO92 luc2 strain. ${ }^{24}$ Age-matched naive mice were used as a rechallenge control. The $P$ values were calculated using Kaplan-Meier analysis with log-rank (Mantel-Cox) test and were in comparison to naive controls.

that parental immunisation can lead to protective mucosal immunity, by yet unidentified mechanism(s). ${ }^{47}$ Using the abovementioned vaccination protocol, $100 \%$ survivability was noted with no clinical signs of disease in immunised mice, irrespective of the mutant used, up to 120 days after the initial immunisation.

To determine long-term humoral immune response generated by the three live-attenuated vaccine strains, splenocytes were harvested from mice ( $n=3-5$ per group per time point) on days 42,63 and 84 after the first immunisation. The total CD19 ${ }^{+}$B-cell population was similar across all groups of mice on all days examined ( $30 \%$ of the live cell population) based on flow cytometry. On day 42 , mice immunised with $\Delta l p p \Delta m s b B:: a i l L 2$, $\triangle l p p \triangle m s b B \quad \Delta p l a$ or the $\Delta l p p \Delta m s b B \quad \Delta a i l$ mutant exhibited significantly increased $\mathrm{CD} 19^{+} \mathrm{CD}_{3} 8^{+} \mathrm{lgG}^{+}$memory B-cell populations $(10.5,7.3$ and $4.2 \%$, respectively) in the spleen compared with animals injected with phosphate-buffered saline (PBS) (1.6\%) (Figure 2a). By day 63, this population decreased in mice immunised with the $\Delta l p p \Delta m s b B$ ::aill2 mutant (3.2\%), which was comparable to the population observed in control (PBS) mice (Figure 2a). In comparison, mice immunised with $\Delta / p p \Delta m s b B \Delta$ ail or $\Delta l p p \triangle m s b B \Delta$ pla mutants continued to show increased or similar population of $\mathrm{CD} 19^{+} \mathrm{CD} 38^{+} \mathrm{lgG}^{+}$memory $\mathrm{B}$ cells $(7.6$ and $6.4 \%$, respectively) on day 63 . By day 84 , these populations decreased in all of the immunised groups of mice, which were similar to those in the PBS-injected mice ( 0.7-1\%) (Figure 2a).

Sera were collected from all mice on days 14, 35, 56, 81 and 112 after the first vaccination for measuring antigen-specific antibody responses (Figure $2 \mathrm{~b}$ ). On day 14 , mice immunised with $\Delta / p p$ $\triangle m s b B \Delta$ ail or $\Delta l p p \Delta m s b B \Delta p l a$ mutants exhibited increased lgG antibody titres (Geometric Mean IgG titres of 15,625) against $Y$. pestis F1-V fusion antigen, representing capsular (F1) and low calcium response $\mathrm{V}$ (LcrV) antigens, compared with mice vaccinated with the $\Delta l p p \Delta m s b B::$ aill 2 mutant (titre of 9,365). By day 35 , a boost in the IgG antibody titres $(46,875)$ occurred after the second immunisation (given on day 21) when mice were immunised with $\Delta l p p \Delta m s b B \Delta$ ail or $\Delta l p p \Delta m s b B \Delta p l a$ mutants. On 
a

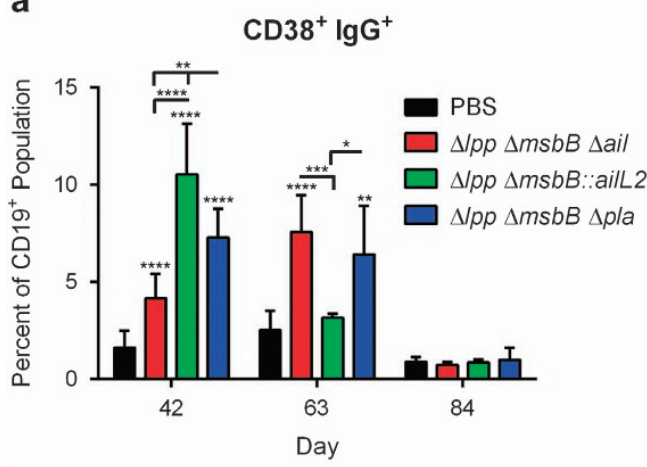

b

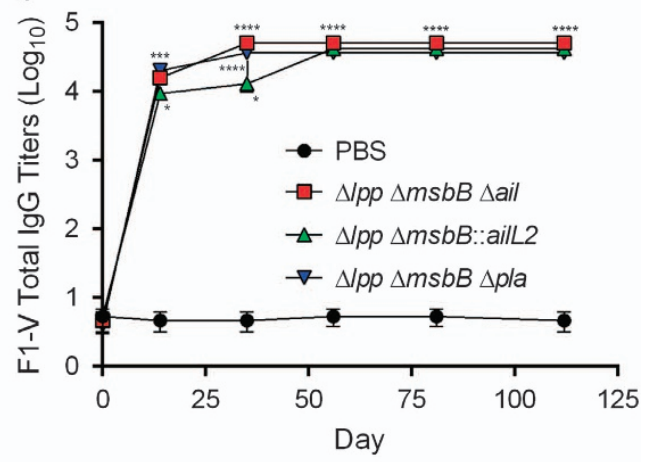

$\lg 2 a$
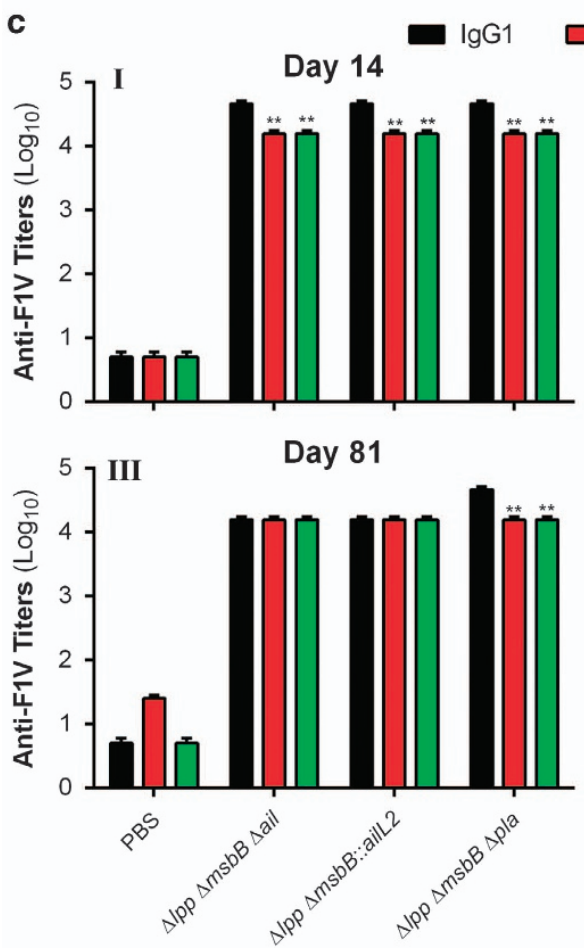
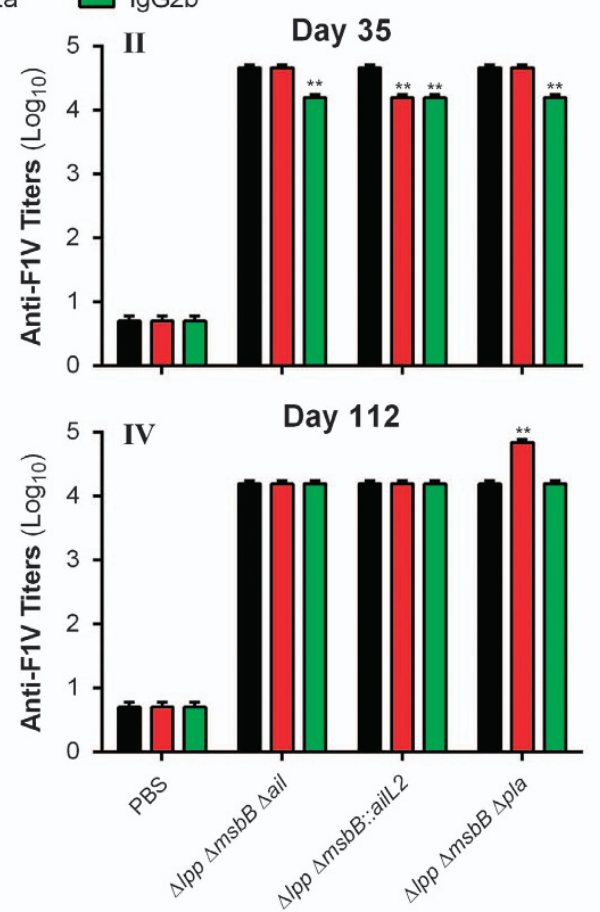

Figure 2. Long-term humoral immune responses in mice immunised with live-attenuated mutants of $Y$. pestis CO92. Mice ( $n=5$ per group/ time point) were immunised by the i.m. route with two doses $\left(2 \times 10^{6} \mathrm{CFU} /\right.$ dose $)$ of $\Delta / p p \Delta m s b B \Delta a i l, \Delta / p p \Delta m s b B:: a i l L 2$ or the $\Delta / p p \Delta m s b B$ $\Delta$ pla mutants on days 0 and 21. Mice injected i.m. with PBS served as controls ( $n=3$ per time point). (a) Spleens were harvested from mice on days 42,63 and 84 . Splenocytes were stained and analysed by Flow cytometry. Per cent $\mathrm{CD}^{+} 8^{+}$IgG ${ }^{+}$(memory B-cell markers) expressing CD $19^{+}$B cells were calculated using FlowJo. Two-way ANOVA with Tukey post hoc was utilised for statistical analysis. (b) Sera were collected from mice on days 0, 14, 35, 56, 84 and 112 after first immunisation. Specific $Y$. pestis IgG was measured using ELISA against the F1-V antigen. Each time point was statistically analysed using a One-way ANOVA with Tukey post hoc. (c) Specific $Y$. pestis IgG isotypes to F1-V antigen in sera collected on day 14 (I), 35 (II), 81 (III) and 112 (IV) were measured by ELISA using isotyping specific secondary antibodies. Each time point was analysed using a two-way ANOVA with Tukey post hoc. ${ }^{*} P<0.05,{ }^{* *} P<0.01,{ }^{* * *} P<0.001$ and ${ }^{* * * *} P<0.0001$ as compared with PBS-injected controls. Horizontal and vertical bars represented differences between groups.

the contrary, a boost to the peak lgG antibody titres $(46,875)$ in the $\Delta l p p \Delta m s b B:: a i l L 2$ mutant-vaccinated mice was attained by day 56 . These antibody titres remained at similar high levels until day 112 in all of the immunised groups of mice.

A significantly higher $\lg G 1$ over $\lg \mathrm{G} 2 \mathrm{a} / \mathrm{b}$ antibody titres were noted in all of the immunised mice on day 14 (Figure 2c-l). After the second vaccine dose, and on days 35 and 56, mice immunised with the $\Delta / p p \triangle m s b B \Delta$ ail and $\Delta / p p \Delta m s b B \quad \Delta p l a$ mutants had balanced Th1-based IgG2a and Th2-based IgG1 antibody responses, whereas mice vaccinated with the $\Delta l p p \Delta m s b B:: a i l L 2$ mutant continued to have higher $\operatorname{lgG} 1$ over $\operatorname{lgG} 2 \mathrm{a}$ titres (Figure 2c-Il; data not shown for day 56). By day 81, balanced Th1-based IgG2a and Th2-based IgG1 antibody titres were observed in mice immunised with the $\Delta l p p \triangle m s b B \Delta$ ail or the $\Delta l p p \Delta m s b B:: a i l L 2$ mutant, whereas the $\Delta l p p \Delta m s b B \Delta p l a$ mutantvaccinated mice exhibited significantly higher lgG1 titres compared with IgG2a/b titres (Figure 2c-III). By day 112, mice immunised with the $\Delta l p p \Delta m s b B \Delta$ ail or the $\Delta l p p \Delta m s b B:: a i l L 2$ mutant maintained balanced Th1-based IgG2a and Th2-based lgG1 antibody titres. However, $\Delta l p p \quad \Delta m s b B$ $\Delta p l a$ mutantvaccinated mice possessed significantly higher lgG2a titres compared with IgG1 antibody titres (Figure 2c-IV).

Overall, all immunised mice maintained high levels of $\operatorname{lgG} 1$, $\lg G 2 a$ and $\lg G 2 b$ antibody titres over the duration of the experiment, albeit some skewing of Th1- and Th2-based immune responses occurred. Importantly, all three aforementioned 

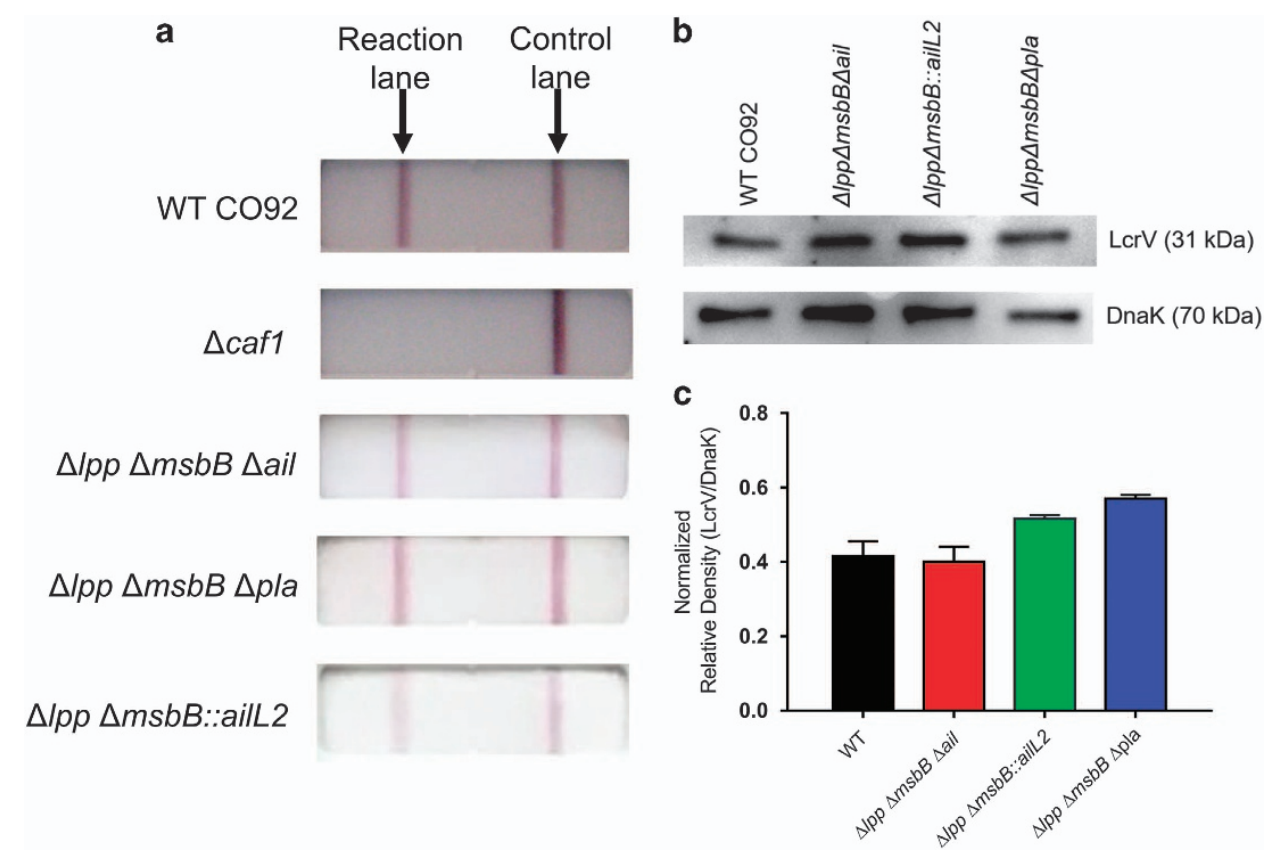

Figure 3. Production of LcrV and F1 by the live-attenuated mutants of $Y$. pestis CO92. To detect F1 production, $100 \mu$ l of each $37^{\circ} \mathrm{C}$ grown bacterial cultures $\left(1 \times 10^{7} \mathrm{CFU}\right)$ was analysed with the F1 antigen capture-based dipstick, and WT CO92 as well as its F1 minus mutant ( $\Delta$ caf1) were used as controls (a). To detect LcrV production, bacterial cultures were first grown at $37^{\circ} \mathrm{C}$ in the presence of $5 \mathrm{mmol} / \mathrm{I}$ EGTA to activate T3SS. Cell pellets were then subjected to western blot analysis with specific anti-LcrV antibodies, and the antibody to DnaK was employed as a control for the sample loading (b). The density of LcrV on the immunoblot for each lane was normalised to that of its corresponding DnaK immunoblot and presented as a bar graph (c).

mutants were metabolically active as no apparent alterations were observed in the production of both F1 and LcrV compared with the WT CO92 based on the F1 antigen capture-based dipstick and Western blot analyses (Figure 3). ${ }^{23,25}$

Long-term cell-mediated immunity after immunisation of mice with live-attenuated mutants of $Y$. pestis $\mathrm{CO} 2$

To examine $T$ cell-mediated immune responses after immunisation, splenocytes were isolated from mice and stained for $T$ cellspecific markers on days 42,63 and 84 . By day 42 , all immunised mice had statistically significant increased population of $\mathrm{CD}^{+}$ cells in the spleen (Figure 4a). On day 84, although the increasing pattern still continued in all three mutant-immunised mice as compared with mice injected with PBS (20.5\%), only mice vaccinated with the $\Delta l p p \triangle m s b B \quad \Delta a i l$ mutant had statistically significant higher $\mathrm{CD}^{+}$population $(29.7 \%)$. The $\mathrm{CD}^{+}$population was 26.5 and $28.4 \%$ in mice immunised with $\Delta l p p \Delta m s b B:: a i l L 2$ and $\Delta l p p \Delta m s b B \Delta$ la mutants, respectively (Figure $4 a$ ).

To further evaluate cell-mediated immune responses in vaccinated mice, $T$ cells were stained for selected cytokines or transcription factors. On days 42 and 63 , interferon (IFN) $-\gamma^{+} \mathrm{CD} 4^{+}$ cell population was significantly increased in mice immunised with the $\Delta l p p \Delta m s b B \Delta$ ail mutant $(\sim 2-2.7 \%)$ or the $\Delta l p p \Delta m s b B$ $\triangle$ pla mutant ( 3.1-3.2\%) compared with PBS-injected mice $(\sim 0.7-1.7 \%)$ (Figure $4 \mathrm{~b}-\mathrm{I})$. On day 84 , although the IFN- $\gamma^{+} \mathrm{CD}^{+}$ cell population remained significantly high in mice immunised with the $\Delta l p p \triangle m s b B \Delta$ ail mutant $(2.7 \%)$, this cell population decreased in $\Delta l p p \triangle m s b B \quad \Delta p l a$ mutant-immunised mice $(0.7 \%)$ (Figure $4 \mathrm{~b}-\mathrm{I}$ ). The IFN- $\gamma^{+} \mathrm{CD}^{+}$cell population in mice vaccinated with the $\Delta l p p \Delta m s b B::$ aill2 mutant $(\sim 1.8 \%)$ was comparable to that of PBS-injected mice $(\sim 1.7 \%)$ on day 42 , increasing significantly on day $63(\sim 2.4 \%)$. However, it dropped to a level similar to that in the PBS-injected mice on day 84 .
$\mathrm{IL}-17 \mathrm{~A}^{+} \mathrm{CD} 4^{+}$cell population increased in all immunised mice on day $42(\sim 0.5-1.3 \%)$ compared with PBS-injected mice $(0.003 \%)$ (Figure 4b-II); however, only mice immunised with the $\Delta l p p \Delta m s b B$ $\triangle$ pla mutant reached statistical significance and had the highest $\mathrm{IL}-17 \mathrm{~A}^{+} \mathrm{CD}^{+}$population compared with all other groups. Importantly, the level of IL-17A ${ }^{+} \mathrm{CD} 4^{+}$cells were further elevated on day 63 in all of the immunised mice ( 1.2-1.9\%) compared with that on day 42 , and was significant higher than that of the PBS-injected mice ( $0.3 \%)$. By day 84 , this subset of population in the immunised mice returned to that of the PBS-injected mice. Interestingly, Foxp ${ }^{+} \mathrm{CD}^{+}$cell population increased significantly in all immunised mice on day $42(\sim 8.6-9.4 \%)$ compared with PBSinjected mice (6.3\%) (Figure 4b-III). On day 63, these levels remained elevated ( 7.2-10.5\%) compared with those in naive mice ( $5 \%)$. By day 84 , this subset of cell population in vaccinated mice returned to that of PBS-injected mice.

Evaluation of long-term protection against pneumonic plague provided by immunisation of mice with live-attenuated mutants of $Y$. pestis $\mathrm{CO} 2$

On day 120 , mice were challenged via the i.n. route with $1.2 \times 10^{4}$ CFU dose $\left(24 L_{50}\right)$ of the WT CO92 luc2 strain (with the luciferase gene) to mimic the pneumonic plague. ${ }^{23-26,48}$ The PBS-injected mice succumbed to infection by day 125 (5 days p.i.) (Figure 5a). Two of these five mice died prior to imaging for bioluminescence. The image in Figure 5b-I (PBS) showed that two of the three remaining control mice were positive for bioluminescence on day 123 ( 3 days p.i.). One animal with the strongest bioluminescence died immediately after the imaging, whereas the other two with somewhat weaker or negative bioluminescence died on day 4 and 5 p.i., respectively. The mouse on the extreme right side in the panel PBS represented an uninfected control for imaging. One animal from each of the $\Delta l p p \Delta m s b B \Delta a i l$ and $\Delta l p p \Delta m s b B:: a i l L 2$ mutant-immunised groups were positive for bioluminescence, and 
a

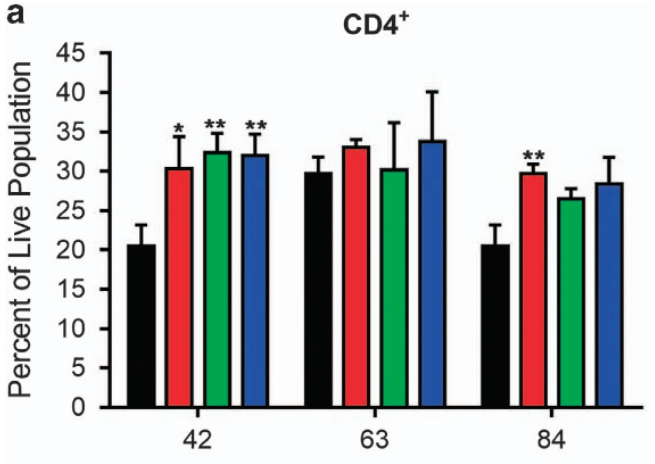

b

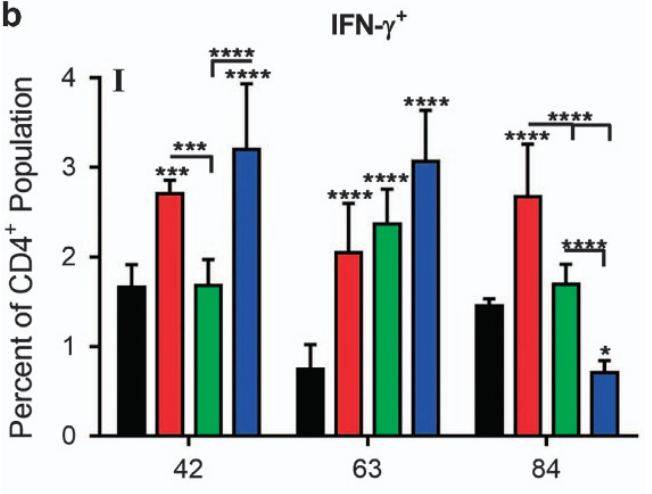

IL-17A ${ }^{+}$

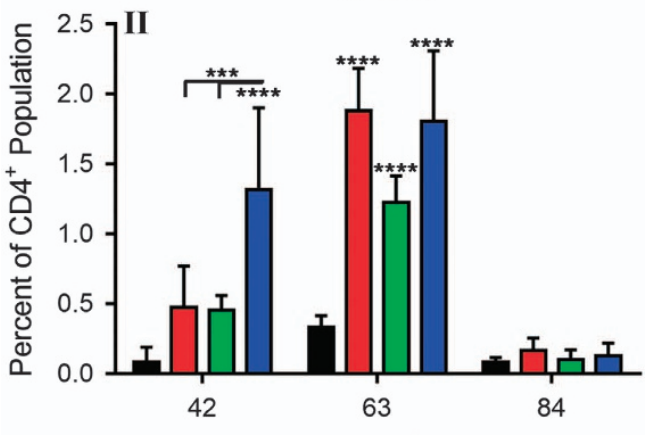

Foxp $^{+}$

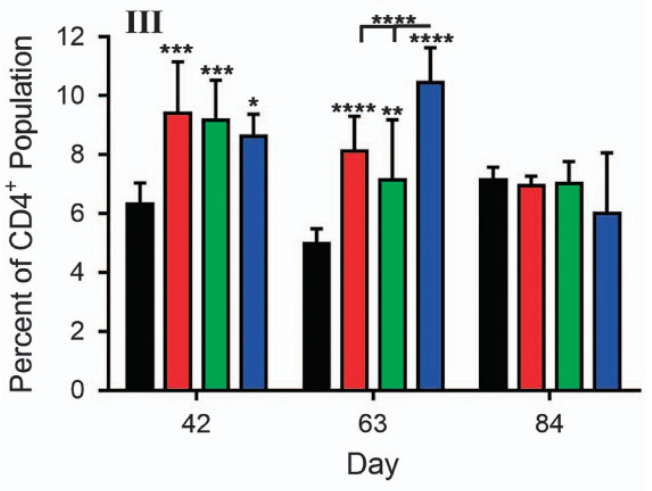

PBS

$\Delta / p p \Delta m s b B:: a i l L 2$

$\square / p p \Delta m s b B \Delta$ ail $\Delta / p p \Delta m s b B \Delta p l a$

the infection was confined to the lungs (Figure $5 \mathrm{~b}$-II and III). These two mice succumbed to infection on day 125 (5 days p.i.), resulting in $80 \%$ animal survival (Figure $5 a$ ). The remaining mice in these groups survived and were negative for bioluminescence on day 10 after challenge, thus suggesting clearance of WT CO92 before day 10 . All of the mice immunised with the $\Delta l p p \Delta m s b B$
Figure 4. Long-term cell-mediated immune responses in mice immunised with live-attenuated mutants of $Y$. pestis CO92. Mice ( $n=5$ per group/time point) were immunised by the i.m. route with two doses ( $2 \times 10^{6} \mathrm{CFU} /$ dose) of $\Delta / p p \Delta m s b B \Delta$ ail, $\Delta / p p \Delta m s b B:: a i l L 2$ or the $\Delta / p p \Delta m s b B \Delta p l a$ mutants on days 0 and 21. Mice were injected i.m. with PBS to serve as controls ( $n=3$ per time point). Spleens were harvested from mice on days 42, 63 and 84 . Splenocytes were stained and analysed by Flow cytometry. (a) Total per cent of $\mathrm{CD}^{+}$(T-helper cell marker) expressing cells was calculated using FlowJo. (b) Per cent of IFN- $\gamma$ (l; Th1 marker), IL-17A (II; Th17 marker) and Foxp3 (III; $\mathrm{T}_{\text {reg }}$ marker) expressing CD4 ${ }^{+}$ cells was calculated. Two-way ANOVA with Tukey post hoc was utilised for determining statistical significance. ${ }^{*} P<0.05$, ${ }^{* *} P<0.01$, ${ }^{* * *} P<0.001$ and $* * * * P<0.0001$ as compared with PBS-injected controls. Horizontal bars represent differences between the indicated groups.

$\Delta$ pla mutant survived exposure to WT CO92, and they were negative for bioluminescence on both days 3 and 10 p.i. (Figures 5a, b-IV).

Evaluation of the immediate innate immune response of vaccinated mice after exposure to WT Y. pestis CO92 in a pneumonic plague model

On day 120, both mutant-immunised- and PBS-injected control mice were exposed to $24 \mathrm{LD}_{50}$ of WT CO92 luc2 strain. On day 124 (4 days p.i.), spleens were harvested from a subset of the challenged mice ( $n=3-4$ per group) to determine innate immune cell response subsequent to the challenge. The total number of CD $11 \mathrm{c}^{+} \mathrm{CD}_{11 \mathrm{~b}^{-}}$resident dendritic cells (DCs) was maximally increased in mice immunised with the $\Delta l p p \Delta m s b B:: a i l L 2$ mutant (6.3\%) compared with the other two groups of vaccinated (with $\Delta l p p \Delta m s b B \Delta$ ail (4.3\%) or $\Delta l p p \Delta m s b B \Delta p l a(4.7 \%)$ mutant) mice (Figure 6a). Importantly, the DC numbers significantly increased in all immunised mice compared with mice that were injected with PBS and exposed to the WT CO92 luc2 strain (2.5\%) (Figure 6a).

The total number of $\mathrm{CD} 80^{+} \mathrm{CD} 86^{+}$cells, which represented activated $\mathrm{CD}_{11} \mathrm{c}^{+} \mathrm{CD}_{11 \mathrm{~b}^{-}} \mathrm{DC}$ populations, was maximally increased in mice immunised with the $\Delta l p p \triangle m s b B \Delta$ ail mutant followed by the $\Delta l p p \Delta m s b B::$ aill2 and $\Delta l p p \Delta m s b B$ spla mutants subsequent to the WT CO92 exposure (Figure $6 \mathrm{~b}-\mathrm{I}$ ). These activated DC cell numbers were in comparison to mice injected with PBS and exposed to WT CO92. Likewise, MHC-II expression was highest in the $C D 11 c^{+} C D 11 b^{-}$cell population isolated from mice vaccinated with the $\Delta l p p \Delta m s b B \Delta$ ail mutant followed by that of $\Delta l p p \Delta m s b B:: a i l L 2$ or $\Delta l p p \Delta m s b B \quad \Delta p l a$ mutants when compared with mice injected with PBS and exposed to WT CO92 (Figure 6b-II).

Evaluation of cytokine producing $\mathrm{CD}^{+} \mathrm{T}$ cells in immunised mice after exposure to WT $Y$. pestis CO92 in a pneumonic plague model Similar to the DC staining above, the isolated splenocytes were stained for $\mathrm{T}$ cell markers to determine immune recall response after exposure to WT CO92, and an additional time point on day 141 (21 days p.i.) was also included. For the 124-day time point, spleens from PBS-injected mice with and without exposure to WT CO92 were used as controls. As all PBS-injected mice, exposed to WT CO92 succumbed to infection by day 141 (21 days p.i.), we only used PBS-injected mice not exposed to WT CO92 as controls for this time point.

On day 124 (4 days p.i.), there were no differences in the total number of $\mathrm{CD}^{+}$cell population in any groups of the immunised and control mice after challenge with WT CO92 (Figure 7a). By day 141 (21 days p.i.), mice immunised with $\Delta l p p \Delta m s b B:: a i l L 2$ or $\Delta l p p$ $\triangle m s b B \quad \Delta$ pla mutants had increased number of total $\mathrm{CD}^{+}$ 


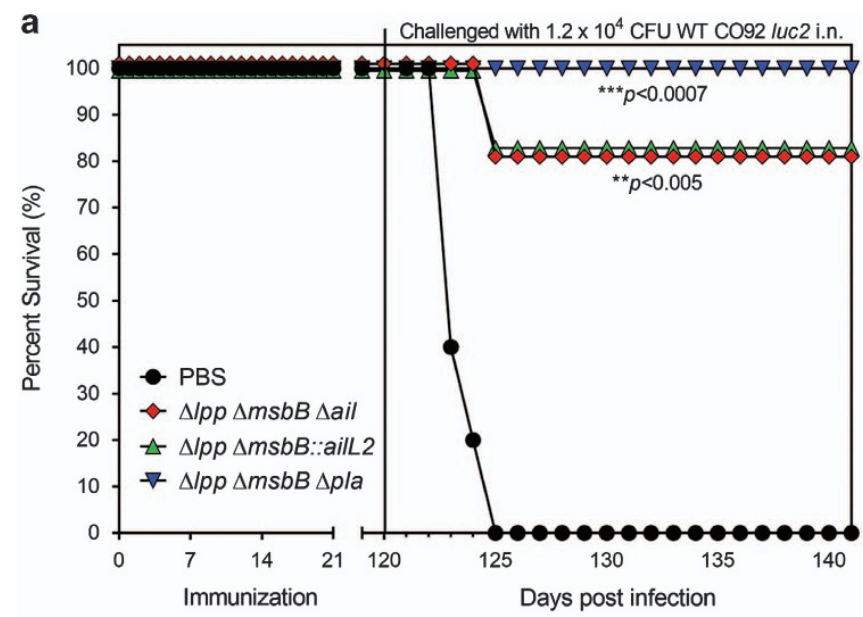

b

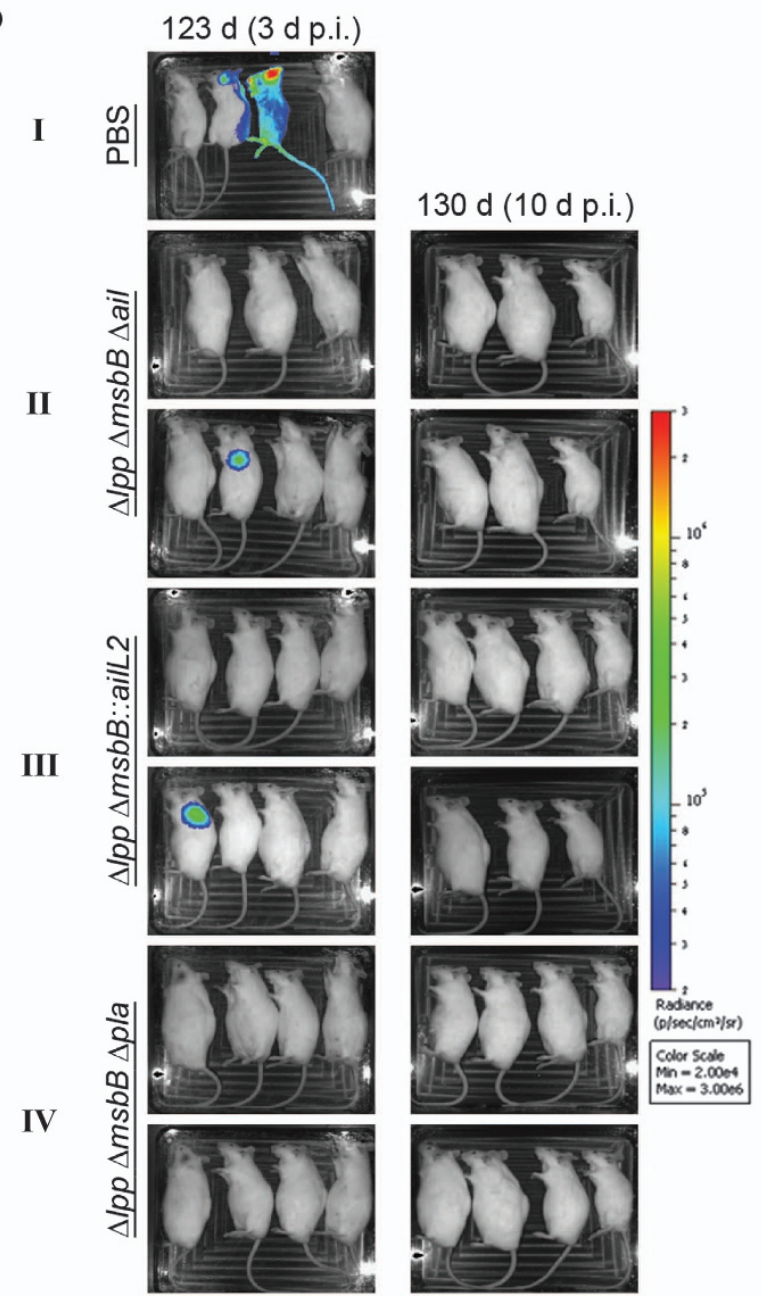

population ( 260-27.5\%) compared with $\Delta l p p \Delta m s b B \Delta$ ail mutantimmunised mice, or those which served as controls (Figure 7a).

Early after exposure to WT CO92 (day 4 p.i.), the spleens of all immunised mice, for example, with $\Delta l p p \Delta m s b B \Delta a i l, \Delta l p p \Delta m s b B::$ aill2 or the $\Delta l p p \triangle m s b B \quad \Delta p l a$ mutants possessed increased percentage of IFN $-\gamma^{+} \mathrm{CD} 4^{+}$cells $(4.6,5.2$ and $7.4 \%$ ), respectively. This was in comparison to mice injected with PBS but not exposed to WT CO92 (1.6\%) as well as to those mice that were injected with PBS and exposed to WT CO92 (1.7\%) (Figure 7b-I). By day 21 p.i., the percentage of IFN- $\gamma^{+} \mathrm{CD}^{+}$cells decreased in all surviving mice
Figure 5. Survival analysis of immunised mice after exposure to WT $Y$. pestis $\mathrm{CO} 92$ in a pneumonic plague model. Mice $(n=5-6$ per group) were immunised by the i.m. route with two doses $\left(2 \times 10^{6}\right.$ CFU/dose) of $\Delta / p p \Delta m s b B \Delta$ ail, $\Delta / p p \Delta m s b B$ ::aill2 or the $\Delta / p p \Delta m s b B$ $\Delta$ pla mutants on days 0 and 21 . Mice were injected i.m. with PBS to serve as controls ( $n=5$ per group). (a) Mice were exposed i.n. on day 120 with $1.2 \times 10^{4}$ CFU $\left(24 L_{50} ; 1 L_{50} \cong 500 \text { CFU }\right)^{24}$ of the WT CO92 luc2 strain (with luciferase gene). The $P$ values were calculated using the Kaplan-Meier analysis with log-rank (Mantel-Cox) test and were in comparison to the naive control. (b) Bioluminescence imaging of mice. Surviving mice after i.n. exposure with $1.2 \times 10^{4}$ CFU of WT CO92 luc2 strain were imaged on days 123 and 130 (days 3 and $10 \mathrm{p}$. i.). The mouse at the extreme right side in each panel was uninfected naive animal to serve as an imaging control. The bioluminescent scale is within the figures and ranges from most intense (red) to least intense (violet).

immunised with $\Delta l p p \Delta m s b B \Delta$ ail, $\Delta l p p \Delta m s b B:: a i l L 2$ or $\Delta l p p \Delta m s b B$ $\triangle$ pla mutants (3, 3.2 and 3.4\%, respectively) (Figure $7 \mathrm{~b}-\mathrm{I})$. However, this cell population was still significantly higher when compared with the control naive mice without exposure to WT CO92 (1\%).

$\mathrm{IL}-17 \mathrm{~A}^{+} \mathrm{CD} 4^{+}$cells were increased in spleens of mice immunised with the $\Delta l p p \Delta m s b B \Delta a i l$ and $\Delta l p p \Delta m s b B \Delta p l a$ mutants compared with mice vaccinated with the $\Delta l p p \quad \Delta m s b B:: a i l l 2$ mutant or injected with PBS after exposure to WT CO92 on day 4 p.i. (Figure $7 \mathrm{~b}-\mathrm{II}$ ). On day 141 (21 days p.i.), the percentage of IL-17A $\mathrm{CD}^{+}$cells was further increased in spleens of mice immunised with the $\Delta l p p \Delta m s b B \Delta$ ail mutant, whereas maintained at a similar level in mice vaccinated with the $\Delta l p p \Delta m s b B \quad \Delta p l a$ mutant compared with day 4 p.i. On the contrary, a robust increase in the population of IL-17A ${ }^{+} \mathrm{CD}^{+}$cells was noted in mice vaccinated with the $\Delta l p p \Delta m s b B:: a i l L 2$ mutant followed by exposure to WT CO92 on day 141 (21 days p.i.) (Figure 7b-II).

On day 124 (4 days p.i.), the Foxp $3^{+} \mathrm{CD}^{+}$cell population was increased in mice vaccinated with $\Delta l p p \Delta m s b B \Delta$ ail, $\Delta l p p \Delta m s b B::$ aill2 or the $\Delta l p p \Delta m s b B \quad \Delta p l a$ mutants (7.8, 5.2 and $6.8 \%$, respectively) when compared with PBS-injected and unexposed naive control (3.6\%) (Figure 7b-III). However, this difference was only significant for the $\Delta l p p \triangle m s b B \Delta$ ail mutant when compared with mice that were injected with PBS and exposed to WT CO92. By day 141 (21 days p.i.), all surviving mice immunised with $\Delta / p p$ $\triangle m s b B \Delta$ ail, $\Delta l p p \Delta m s b B:: a i l L 2$ or $\Delta l p p \Delta m s b B \Delta p l a$ mutants had increased $\mathrm{Foxp}^{+} \mathrm{CD}^{+}$cells $(15.5,14.7$ and $12.5 \%$, respectively), compared with control mice (7.4\%) (Figure $7 \mathrm{~b}-\mathrm{III})$.

Evaluation of humoral and cell-mediated immunity in the mutantimmunised rats necessary for protection against WT Y. pestis CO92 challenge in a pneumonic plague model

On the basis of the mouse data presented above, both $\Delta / p p$ $\triangle m s b B \Delta$ ail and $\Delta l p p \Delta m s b B \Delta p l a$ mutants elicited slightly better humoral and cell-mediated immune responses than that of the $\Delta l p p \Delta m s b B:: a i l L 2$ mutant. Therefore, these two mutants were further evaluated in a rat model of pneumonic plague to authenticate mouse data.

Similar to the mouse model, inbred Brown Norway rats were immunised with two i.m. doses $\left(2.5 \times 10^{6} \mathrm{CFU} /\right.$ dose, 21 days apart) of the selected mutants, and rats receiving PBS injection served as a control. Sera were collected from all rats on days $0,14,35,56,77$ and 88 after the first vaccination for measuring antigen-specific antibody responses. As shown in Figure $8 \mathrm{a}$, the immunised rats in both immunisation groups exhibited high $\operatorname{lgG}$ antibody titres (Geometric Mean IgG titres of 9,325) against $Y$. pestis F1-V fusion antigen on day 14. More specifically, in rats immunised with the $\triangle l p p \quad \triangle m s b B \quad \triangle a i l$ mutant, the lgG antibody titres remained plateaued until day 56 with a slight decrease on day 77 and then maintained at the same level to the last examining day (day 88). 
a

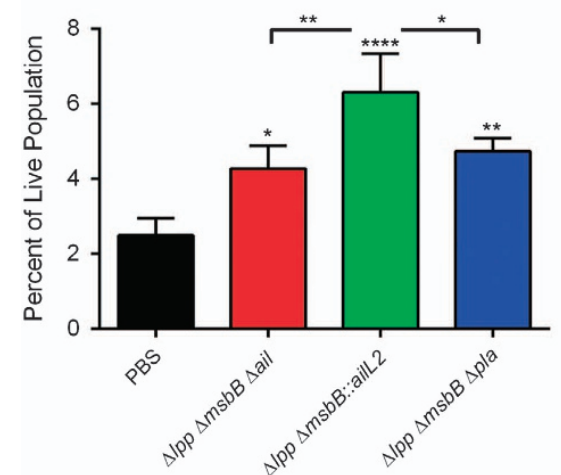

b

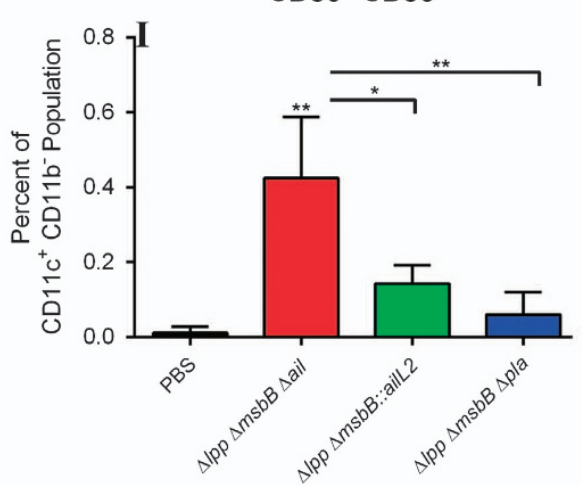

MHC-II+

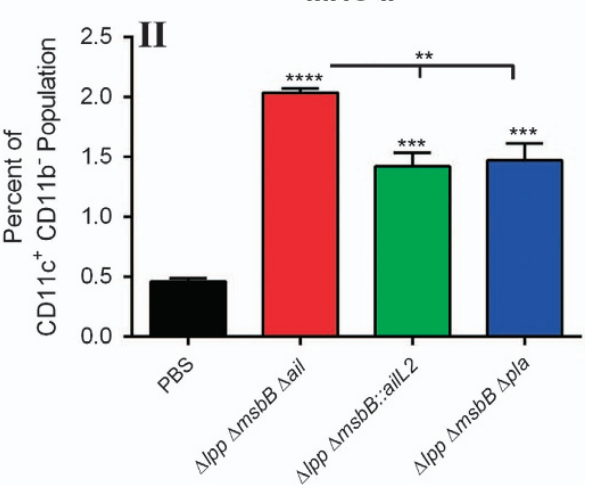

Figure 6. Innate immune responses in mutant-immunised mice after exposure to WT Y. pestis CO92 in a pneumonic plague model. Mice were immunised by the i.m. route with two doses ( $2 \times 10^{6}$ CFU/dose) of $\Delta / p p \Delta m s b B \Delta$ ail, $\Delta / p p \Delta m s b B:: a i l L 2$ or the $\Delta / p p \Delta$ msbB $\Delta p l a$ mutants on days 0 and 21. Mice i.m. injected with PBS served as controls. On day 120 , all mice were exposed i.n. to $1.2 \times 10^{4} C_{C F}\left(24 L_{50} ; L^{2} D_{50} \cong 500\right.$ CFU) ${ }^{24}$ of the WT CO92 luc2 strain. Spleens were harvested from mice ( $n=3-4$ per group) on day 124 (days 4 p.i.). Splenocytes were stained and analysed by Flow cytometry. (a) Total per cent of $C D 11 c^{+} C D 11 b^{-}$(resident DC markers) expressing cells was calculated using FlowJo. (b) Per cent of $\mathrm{CD}^{+} 0^{+} \mathrm{CD} 86^{+}$(I; activation markers) and MHC-II+ (II) expressing DCs were also calculated. Two-way ANOVA analysis with Tukey post hoc was utilised for determining statistical significance. ${ }^{*} P<0.05$, ${ }^{* *} P<0.01$, ${ }^{* *} P<0.001$ and ${ }^{* * *} P<0.0001$ as compared with PBS-injected controls. Horizontal bars represent differences between the indicated groups.

On the other hand, by day 35, a boost in the $\lg \mathrm{G}$ antibody titres $(46,875)$ occurred in rats immunised with the $\Delta l p p \Delta m s b B \Delta p l a$ mutant and remained high until day 88 .

To evaluate $\mathrm{CD}^{+} \mathrm{T}$ cell-mediated immune responses in vaccinated rats, splenocytes ( $n=3$ per group) were isolated on day 42. Although all groups of rat (both immunised and PBSinjected control) had similar number of total $\mathrm{CD} 4^{+}$cell populations ( 31.4-33.9\%), significantly increased IL-17A $\mathrm{A}^{+} \mathrm{CD} 4^{+}$cell population was observed in both groups of immunised rats $(\sim 1.2-2 \%)$ compared with the PBS-injected control rats (0.2\%) (Figure $8 \mathrm{~b}$ ). Furthermore, rats immunised with the $\Delta l p p \Delta m s b B \Delta p l a$ mutant had higher $\mathrm{IL}-17 \mathrm{~A}^{+} \mathrm{CD} 4^{+}$population than that of animals vaccinated with the $\Delta l p p \triangle m s b B \Delta$ ail mutant (Figure $8 \mathrm{~b}$ ). The IFN $-\gamma^{+} \mathrm{CD}^{+}$cell population also increased in both mutantimmunised rats ( 15.5-19.9\%) as compared with the PBS-injected control rats $(\sim 8.5 \%)$; however, a statistical significance was not achieved (data not shown).

To further evaluate the vaccine efficacy of the two mutants, the immunised rats ( $n=6$ per group) were challenged via the i.n. route with WT CO92 luc2 strain at the dose of either $2.3 \times 10^{4}$ CFU (46 $\mathrm{LD}_{50}$ ) on day 43 to evaluate short-term protection or $1.6 \times 10^{4} \mathrm{CFU}$ $\left(31 \mathrm{LD}_{50}\right.$ ) on day 91 to evaluate long-term protection. As shown in Figure $8 c, d$, all the PBS-injected control rats succumbed to infection. On the contrary, $100 \%$ survival was noted in rats immunised with either the $\Delta l p p \Delta m s b B \Delta a$ al or the $\Delta l p p \Delta m s b B$ $\Delta$ pla mutant. Most importantly, no WT CO92 luc2 strain were detected in the blood and organs (lungs, liver and spleen) from both groups of immunised rats 14 days after challenge for the long-term protection assessment, indicating that the challenged bacterium was cleared from the immunised rats.

\section{DISCUSSION}

It is crucial that a potential vaccine candidate(s) demonstrates long-term immune responses and protection. This is the first study to examine several components of the immune response generated after immunisation of mice and rats with the above three live-attenuated mutants over a period of 3-4 months.

The kinetics of memory B-cell production in $Y$. pestis EV76 vaccine strain-immunised mice has been reported. ${ }^{49}$ Similar to our protocol, mice were immunised i.m. with two doses $\left(8 \times 10^{7} \mathrm{CFU} /\right.$ dose) of EV76 (21 days apart) and splenocytes harvested periodically after immunisation. ${ }^{49}$ However, CD38 and $\operatorname{lgD}$ expressing $\mathrm{CD}_{19} \mathrm{CD}^{+} 7^{+}$population was evaluated in that study. CD27 is not considered as an appropriate marker for memory B cells in mice, ${ }^{50,51}$ and the lack of CD27 expression on memory $B$ cells has been previously reported. ${ }^{52}$ CD38 has been widely accepted as a marker of memory $B$ cells as antigen-specific lgG1 B cells with high CD38 expression and similar characteristics to recirculating memory $B$ cells are apparent weeks after immunisation. $^{50,53}$ Although $\operatorname{lgD}$ and $\lg \mathrm{G}$ are produced by activated B cells, we designated memory B-cell population as CD38 and IgG producing CD19 ${ }^{+}$cells. By day 7, memory B-cell populations increased in EV76-immunised mice in the spleen. ${ }^{49}$ However, this population of cells sharply decreased by day $56 .{ }^{49}$ Memory B cells in the $\Delta l p p \Delta m s b B:: a i l L 2$ mutant-immunised mice behaved similar to those in the EV76-immunised animals with increases in the $\mathrm{CD} 19^{+} \mathrm{CD} 38^{+} \mathrm{IgG}^{+}$cell population on day 42 which decreased to the levels seen in naive mice by day 63 (Figure 2a). However, memory B-cell population in $\Delta l p p \Delta m s b B$ $\triangle a i l$ and $\Delta l p p \Delta m s b B \Delta p l a$ mutant-immunised mice increased or remained high through day 63 and declined to levels seen in naive mice only on day 84 (Figure $2 a$ ).

In terms of antibody production, total lgG titres in the $\Delta / p p$ $\Delta m s b B:: a i l L 2$ mutant-immunised mice reached a maximal level on day 56 and then plateaued, whereas mice immunised with the other two mutants, $\Delta l p p \Delta m s b B \quad \Delta$ ail and $\Delta l p p \Delta m s b B \Delta p l a$, showed maximum lgG titres by day 35 and then plateaued (Figure $2 \mathrm{~b}$ ). In contrast, the total memory B-cell population peaked at day 42 in the $\Delta l p p \Delta m s b B:: a i l L 2$ mutant-immunised mice, which then decreased to levels of PBS-injected, naive mice by day 63 (Figure 2a). Interestingly, mice immunised with the other two mutants were capable of sustaining memory B-cell populations until day 63 (Figure 2a). These differences in time to peak antibody titres versus the maximum percentage of memory B-cell population in the $\Delta l p p \Delta m s b B:: a i l L 2$ mutant-immunised mice (Figure 2a,b) could be attributed to low avidity of the IgG antibodies to F1-V antigens of $Y$. pestis early during vaccination before switching to high-affinity antibodies later during immunisation. Alternatively, these memory B cells from $\Delta l p p \Delta m s b B$ ::aillL2 mutant-immunised mice might be secreting less lgG per cell compared with that of the memory B cells of $\Delta l p p \Delta m s b B \Delta a i l$ and $\Delta l p p \Delta m s b B \Delta p l a$ mutant-immunised mice because of a high proportion of unswitched memory B cells early during immunisation. ${ }^{54}$ 


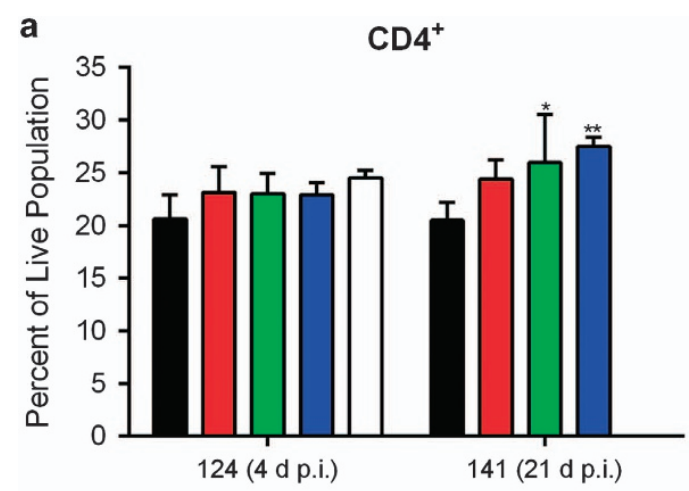

b

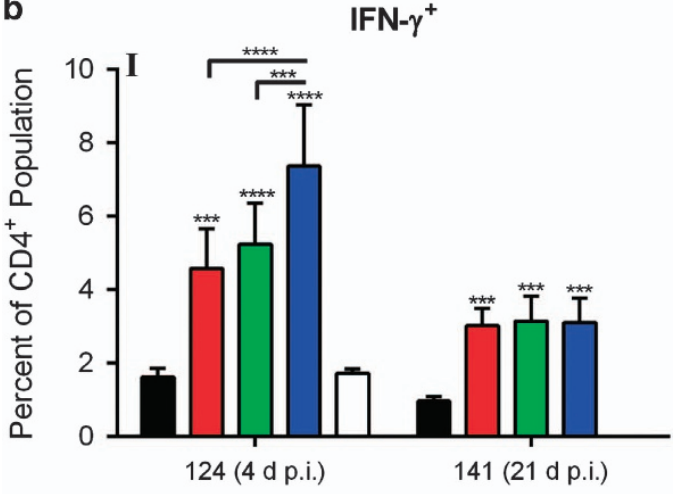

IL-17A
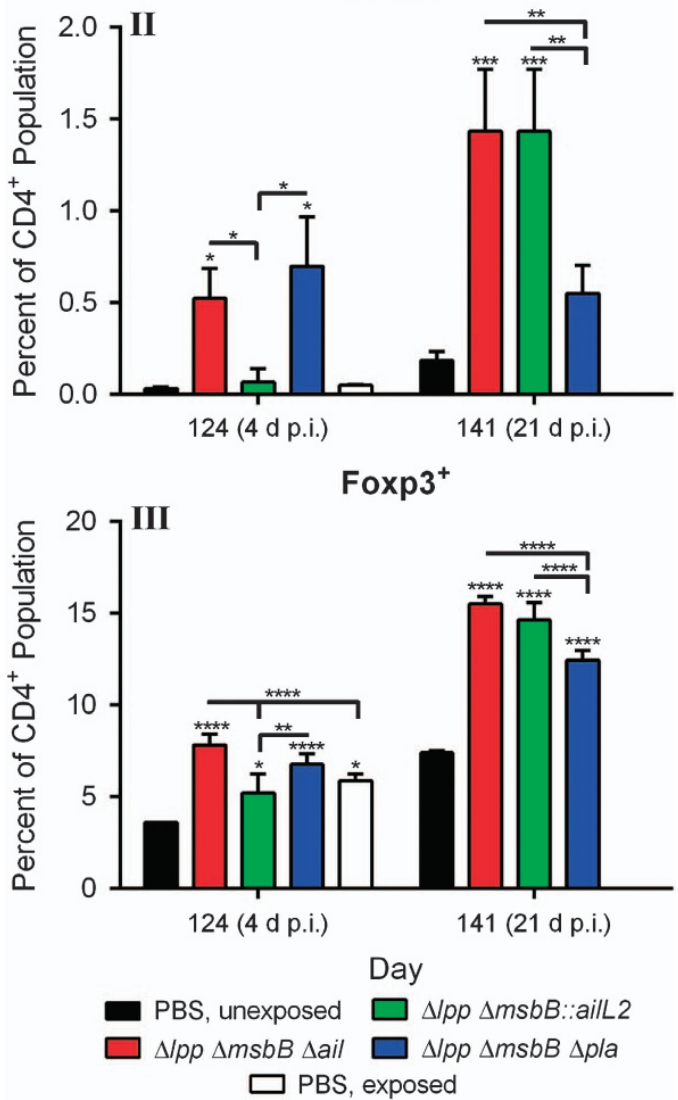

PBS, exposed
Figure 7. Cell-mediated immune responses in mutant-immunised mice after exposure to WT $Y$. pestis CO92 in a pneumonic plague model. Mice were immunised by the i.m. route with two doses $\left(2 \times 10^{6} \mathrm{CFU} /\right.$ dose $)$ of $\Delta / p p \Delta m s b B \Delta$ ail, $\Delta / p p \Delta m s b B::$ aillL2 or the $\Delta / p p$ $\Delta m s b B \Delta$ pla mutants on days 0 and 21 . Mice were exposed i.n. on day 120 with $1.2 \times 10^{4}$ CFU (24 LD $50 ; 1 L_{50} \cong 500$ CFU) ${ }^{24}$ of the WT CO92 luc2 strain. Mice i.m. injected with PBS and then either exposed or not exposed to WT CO92 luc2 served as controls. Spleens were harvested from surviving mice (3-5 per group) on days 124 (4 days p.i.) and 141 (21 days p.i.). Splenocytes were stained and analysed by Flow cytometry. (a) Total per cent of CD4 ${ }^{+}$(T-helper cell marker) expressing cells was calculated using FlowJo. (b) Per cent of IFN- $\gamma$ (I; Th1 marker), IL-17A (II; Th17 marker) and Foxp3 (III; $\mathrm{T}_{\text {reg }}$ marker) expressing $\mathrm{CD}^{+}$cells was calculated. Two-way ANOVA analysis with Tukey post hoc was utilised for determining statistical significance. ${ }^{*} P<0.05,{ }^{* *} P<0.01,{ }^{* * *} P<0.001$ and ${ }^{* * * *} P<0.0001$ as compared with PBS-injected controls. Horizontal bars represent differences between the indicated groups.

Mice immunised i.m. with two doses ( $8 \times 10^{7}$ CFU/dose) of EV76 strain ( 21 days apart) had lower total F1-specific lgG titres $(10,000-$ $15,000$ on day 42$).^{55}$ These titres decreased below 10,000 by day 70 , and further declined before attaining a steady state level $(1,400)$ by day $322 .{ }^{55}$ In comparison, mice vaccinated with our liveattenuated mutants at a lower dose $\left(2 \times 10^{6} \mathrm{CFU} /\right.$ dose $)$ were not only able to achieve total F1-V specific lgG titres of 46,875 by day $35-56$ but were able to maintain these maximum titres until day 112 (Figure 2b).

Overall, all three live-attenuated mutants stimulated longlasting $T$ cell-mediated immune responses capable of protecting mice from developing subsequent pneumonic plague. Our data generally indicated an increase in IFN- $\gamma^{-}$, IL-17A- and Foxp3expressing $\mathrm{CD}^{+} \mathrm{T}$ cells after immunisation (Figure 4). A similar trend was also noted when these mutant-immunised mice were subsequently exposed to WT CO92 in a pneumonic model (Figure 7). All immunised mice that survived WT CO92 luc2 strain challenge rapidly cleared the bacteria ( 3 days p.i.) as measured by bioluminescence (Figure $5 \mathrm{~b}$ ), possibly due to increased production of IFN $-\gamma$ by $\mathrm{CD}^{+}$cells (Figure $7 \mathrm{~b}-\mathrm{I}$ ). IFN- $\gamma$ promotes macrophage activation facilitating defence against bacterial pathogens, ${ }^{56}$ and it has been shown that IFN- $\gamma$ as well as tumour necrosis factor-a are important co-determinants of antibody-mediated protection against pneumonic plague. ${ }^{57}$ Consequently, the increased presence of $\mathrm{IFN}^{-} \gamma^{+} \mathrm{CD}^{+}$cells in conjunction with $\mathrm{F} 1-\mathrm{V}$ specific neutralising antibody production could augment opsonization and clearance of $Y$. pestis.

Th17 cells are potent secretors of IL-17A, and it has recently been shown that IL-17A provides an antibody-independent heterologous protection of the host against many pathogenic bacterial infections, including $Y$. pestis. ${ }^{58,59}$ For example, IL-17A was induced by the intranasal immunisation of mice with the $Y$. pestis strain D27-pLpxL KIM/D27 engineered to produce Escherichia coli LpxL, which increases TLR-4 activation by LPS of Y. pestis. ${ }^{60}$ Thus, IL-17A contributed significantly to T cell-mediated defence against pulmonary $Y$. pestis infection. ${ }^{59}$ Consistent with previous reports, ${ }^{58,59}$ we also showed $\Delta l p p \Delta m s b B \Delta p l a$ mutantimmunised mice had the highest increase in IL-17A producing $\mathrm{CD}^{+}$cells immediately after WT CO92 exposure (Figure 7b-II) resulting in efficient clearance of the invading pathogen. Importantly, the IL-17A ${ }^{+} \mathrm{CD} 4^{+}$cell population decreased in the $\Delta l p p \Delta m s b B \Delta$ pla mutant-immunised mice 21 days post WT CO92 exposure (Figure $7 \mathrm{~b}$-II) signifying a possible faster resolution of inflammation, which is desirable in a potential vaccine.

In contrast, mice vaccinated with $\Delta l p p \Delta m s b B \quad \Delta a i l$ or $\Delta / p p$ $\triangle m s b B:: a i l L 2$ mutants and subsequently challenged with WT CO92 had increased IL-17A producing CD4 ${ }^{+}$cells 21 days p.i. (Figure 7b-II). Thus, these mice would most likely had somewhat of a prolonged 
a

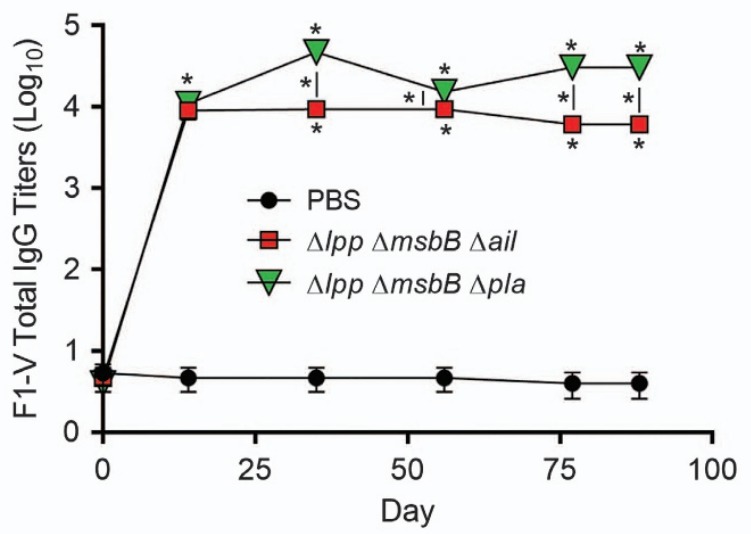

c

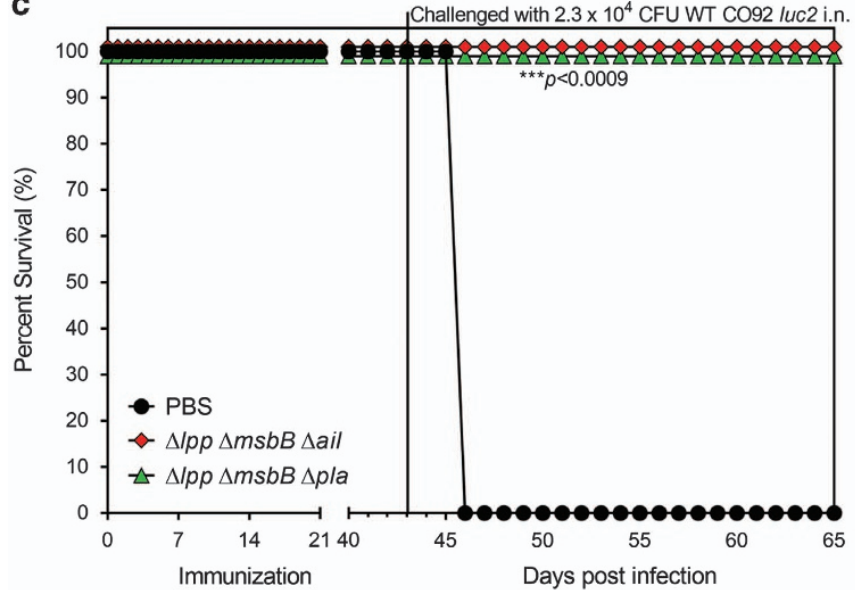

b

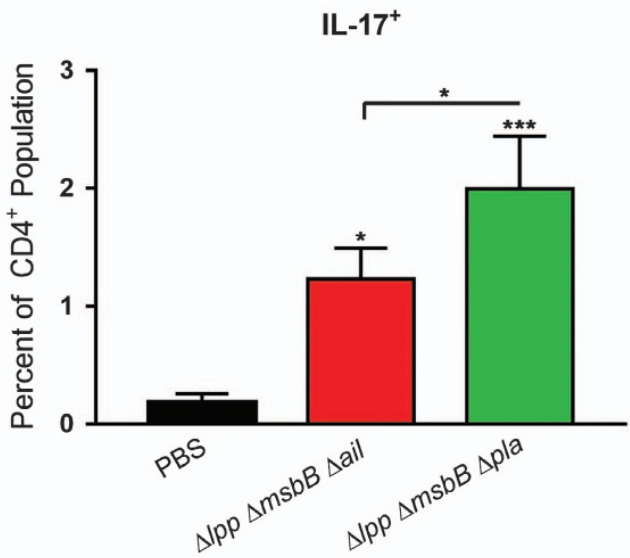

d

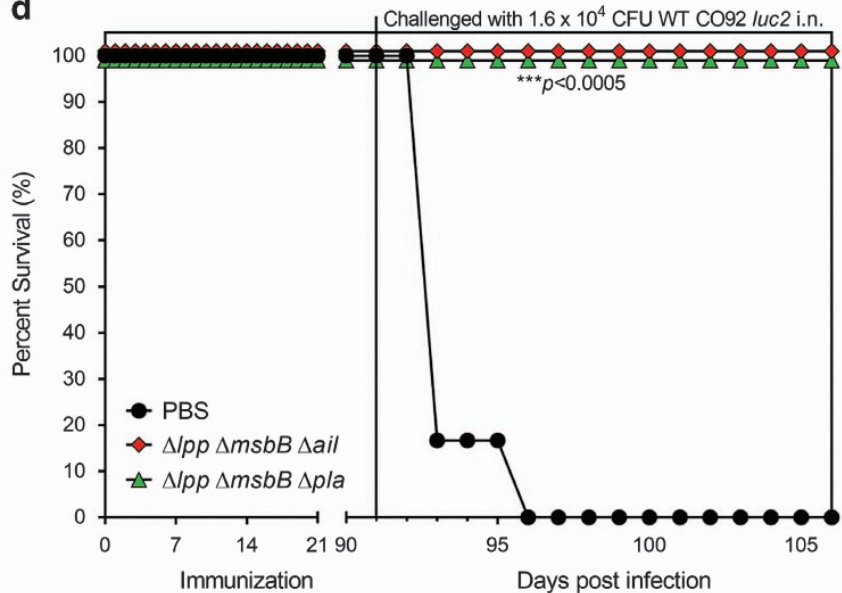

Figure 8. Immune response and protection in rats conferred by immunisation with mutants of $Y$. pestis CO92 against pneumonic plague. Brown Norway rats were immunized by the i.m. route with two doses $\left(2 \times 10^{6} \mathrm{CFU} /\right.$ dose $)$ of $\Delta / p p \Delta m s b B \Delta$ ail or the $\Delta / p p \Delta m s b B \Delta p l a$ mutant on days 0 and 21. Rats were injected i.m. with PBS to serve as controls. (a) Sera were collected from rats on days $0,14,35,56,77$ and 88 after first immunization. Specific $Y$. pestis IgG was measured using ELISA against the F1-V antigen. Each time point was statistically analysed using a one-way ANOVA with Tukey post hoc. (b) Spleens were harvested from rats on days 42 . Splenocytes were stained and analysed by Flow cytometry. IL-17A ${ }^{+}$(Th17 marker) expressing CD4 ${ }^{+}$cells were calculated. Two-way ANOVA with Tukey post hoc was utilised for determining statistical significance. ${ }^{*} P<0.05$ and ${ }^{* *} P<0.001$ as compared with PBS-injected controls. Horizontal and vertical bars represented differences between groups. Rats were challenged via the i.n. route with WT CO92 luc2 strain at the dose of either $2.3 \times 10^{4}$ CFU (46 LD 50 ) on day 43 (c) or $1.6 \times 10^{4} \mathrm{CFU}\left(31 \mathrm{LD}_{50}\right)$ on day 91 (d). The survival of rats was recorded and plotted. The $P$ values were calculated using the Kaplan-Meier analysis with log-rank (Mantel-Cox) test and were in comparison to the naive control.

inflammatory response after exposure to WT CO92; however, not to an extent to cause any adverse histopathological lesions in immunised mice. ${ }^{25}$ Interestingly, production of IL-17A from T cells was also observed in our previous study when isolated T cells from $\Delta l p p \Delta m s b B \Delta a i l$ and $\Delta l p p \Delta m s b B:: a i l L 2$ mutant-immunised mice were co-cultured with antigen-presenting cells, which had been exposed to heat-killed WT CO92. ${ }^{25}$

Foxp3 is a transcription factor and marker for $\mathrm{T}_{\text {reg }}$ cells (Foxp3 ${ }^{+}$ $\left.\mathrm{CD}^{+}\right)$, which are primarily responsible for dampening immune responses. Recent studies have revealed that $\mathrm{T}_{\text {reg }}$ cells can promote protective Th17-associated immune responses against bacterial infections. ${ }^{61,62}$ Interestingly, both Foxp3 ${ }^{+}$and IL-17A $\mathrm{CD}^{+}$cells were concurrently increased both after immunisation as well as after WT CO92 challenge (Figures 4b and 7b). However, a direct link between $T_{\text {reg }}$ cells and Th17-based protective immune responses against $Y$. pestis still needs further investigation.

Consistent with the above-mentioned data, all mutantimmunised mice had increased DC population expressing MHC-II (Figure $6 \mathrm{~b}-\mathrm{II}$ ), which is required for antigen presentation to $\mathrm{CD}^{+}$ cells. ${ }^{63}$ An increasing trend in the activation of DCs was noted for all mutant-immunised mice, which attained statistical significance for the $\Delta l p p \triangle m s b B \Delta$ ail mutant. Overall, our results indicated immunisation of mice with any of these mutants could successfully induce activation of an innate immune response after exposure to WT CO92. Most importantly, all three live-attenuated mutants stimulated both long-term humoral- and cell-mediated immune responses, which protected mice against exposure to highly lethal pneumonic challenge (Figure 5).

In the second animal model of pneumonic plague, both the $\Delta l p p \Delta m s b B \Delta a i l$ and $\Delta l p p \Delta m s b B \Delta p l a$ mutants also stimulated robust humoral and cell-mediated immune responses, which provided both short and long-term protection to rats (100\%) against WT CO92 pneumonic challenge (Figure 8). The significantly increased IL- $17 \mathrm{~A}^{+} \mathrm{CD} 4^{+}$population in the immunised rats further highlighted the importance of IL-17 against $Y$. pestis infection.

In addition to efficiency, safety is another important aspect for vaccine development. Recently, we have shown that both the $\Delta l p p \Delta m s b B \quad \Delta$ ail and $\Delta l p p \Delta m s b B:: a i l L 2$ mutants are safe liveattenuated vaccine candidates due to their quick clearance from 
injection site by $24-48 \mathrm{~h}$ after vaccination, and these mice had no histopathological lesions during immunisation. ${ }^{25}$ Our extensive data with the $\Delta l p p \Delta m s b B \Delta a i l$ mutant ${ }^{23,25}$ led to its exclusion from the $C D C$ select agent list. In this study, we have further demonstrated that the WT CO92 luc2 challenge strain was efficiently cleared from the immunised mice and rats after 10-14 days post challenge as examined by using either IVIS or the plate count method. Our future goals are to obtain permission from the CDC to exclude $\Delta l p p \Delta m s b B:: a i l L 2$ and $\Delta l p p \Delta m s b B \Delta p l a$ mutants from the select agent list, allowing safe production of these vaccines under biosafety level 2 precautions. We will further evaluate safety of these live-attenuated vaccine candidates in immunocompromised mice, study in more depth their immune protection mechanisms, and to finally examine efficacy of these vaccines in non-human primates.

\section{MATERIALS AND METHODS}

$Y$. pestis and recombinant $E$. coli strains were grown as described by us previously. ${ }^{23,24,26}$ All of our studies were performed in a Tier-1 select agent facility within the Galveston National Laboratory (GNL), UTMB.

\section{Creation of the $\Delta l p p \Delta m s b B \Delta$ pla mutant of $Y$. pestis CO92}

The in-frame deletion of the $m s b B$ gene from the $\Delta l p p \Delta$ pla double mutant of $Y$. pestis CO92 was prepared using the suicide vector pDMS197 followed by homologous recombination as described previously by our laboratory. ${ }^{26}$ The in-frame deletion of the $m s b B$ gene was confirmed by polymerase chain reaction (PCR) analysis employing specific primers ${ }^{26}$ as well as by DNA sequencing of the flanking regions to the $m s b B$ gene on the chromosome.

\section{Production of LcrV and F1 by the live-attenuated mutants of Y. pestis $\mathrm{CO} 92$}

WT CO92 and the $\Delta l p p \Delta m s b B \Delta a i l, \Delta l p p \Delta m s b B:: a i l L 2$. and $\Delta l p p \Delta m s b B \Delta p l a$ mutants were grown overnight in heart infusion broth (HIB) at $28^{\circ} \mathrm{C}$ and then diluted 1:20 in $5 \mathrm{ml} \mathrm{HIB}$ supplemented with $5 \mathrm{mM}$ EGTA. Cultures were incubated at $28{ }^{\circ} \mathrm{C}$ for $2 \mathrm{~h}$ and then at $37{ }^{\circ} \mathrm{C}$ (to activate the T3SS) for an additional $3 \mathrm{~h}$. The cell pellets were dissolved in SDS-PAGE buffer and analysed with anti-LcrV antibodies (Santa Cruz Biotechnology, Santa Cruz, CA, USA). The anti-DnaK monoclonal antibody (Enzo Life Sciences, Boston, MA, USA) was employed for analysis and normalisation of protein concentrations in cell pellets. The density of the immunoblots was analysed by using Image Studio Lite Version 5.2 (Li-Cor, Lincoln, NE, USA). To detect F1 production, $100 \mu \mathrm{l}$ of each $37^{\circ} \mathrm{C}$ grown bacterial cultures $\left(1 \times 10^{7} \mathrm{CFU}\right)$ was analysed with the $\mathrm{F} 1$ antigen capture-based dipstick (Plague BioThreat Alert test strips, Tetracore, Inc., Rockville, MD, USA) as we previously described. ${ }^{23,25}$

\section{Animal studies}

Six-to-eight-week old, female Swiss-Webster mice were purchased from Taconic Laboratories (Germantown, NY, USA), and four-to-five-week old (50-75 g) Brown Norway female rats were purchased from Charles River (Houston, TX, USA). The animal studies were performed in the Animal Biosafety Level (ABSL)-3 facility under an approved Institutional Animal Care and Use Committee protocol.

Attenuation. Mice were infected by the i.n. route with one dose of $2.5 \times 10^{6} \mathrm{CFU} / 40 \mu \mathrm{l}$ or $5 \times 10^{6} \mathrm{CFU} / 40 \mu \mathrm{l}$ of the $\Delta / p p \Delta m s b B \Delta$ pla mutant, and mice i.n. infected with $2.5 \times 10^{6} \mathrm{CFU} / 40 \mu \mathrm{l}$ of WT CO92 served as control. $^{23,24}$ Animals were assessed for morbidity and/or mortality for twenty-two days. The surviving mice were then rechallenged by the i.n. route with $1.8 \times 10^{4} \mathrm{CFU} / 40 \mu \mathrm{l}\left(36 \mathrm{LD}_{50}\right)$ of the bioluminescent WT Y. pestis CO92 luc2 strain. ${ }^{23}$ The naive mice served as rechallenge controls.

Immunisation. Mice were immunised by the i.m. route with two doses $\left(2 \times 10^{6} \mathrm{CFU} / 100 \mu \mathrm{l}\right)$ of the $\Delta l p p \Delta m s b B \Delta$ ail, $\Delta l p p \Delta m s b B::$ aill 2 or the $\Delta l p p$ $\triangle m s b B \Delta$ pla mutant. One group of mice received PBS in lieu of bacteria, thus representing a naive, unimmunized control. Two doses of the vaccine were given in a $50 \mu \mathrm{l}$ volume in each of the hind legs 21 days apart. ${ }^{25}$
Animals were assessed for morbidity and/or mortality over the duration of vaccination.

Antibody production. Retro-orbital bleeding of all mice occurred on days $0,14,35,56,81$ and 112. Sera were filtered by using Costar $0.1-\mu \mathrm{m}$ centrifuge tube filters (Corning Inc., Corning, NY, USA). ELISA plates were coated with the F1-V fusion protein $(1 \mathrm{ng} / \mathrm{ml}$, BEl Resources, Manassas, VA, USA) overnight at $4{ }^{\circ} \mathrm{C}^{23,24,26}$ Total $\lg G$ and antibody isotypes (IgG1, IgG2a and $\lg \mathrm{G} 2 \mathrm{~b}$ ) against $\mathrm{F} 1-\mathrm{V}$ in the sera (1:5 serially diluted) of all mice were determined as we previously described. ${ }^{23,25}$

Organ harvesting. To evaluate immunogenicity of the mutant strains, spleens from three control and five immunised mice (per group per time point) were isolated on days 42,63 and 84 . In addition, another set of mice (immunised and control, $n=8-10$ per group) were first exposed to $1.2 \times 10^{4} \mathrm{CFU} / 40 \mu \mathrm{l}\left(24 \mathrm{LD}_{50}\right)$ of the bioluminescent WT Y. pestis CO92 luc2 strain on day 120 after the first immunisation. Spleens were then isolated from these surviving mice ( $n=3-5$ per group) on either day 124 (4 days p.i.) or on day 141 (21 days p.i.). The PBS-injected mice without exposure to WT CO92 luc2 $(n=3)$ served as an additional control for the T cell experiment. Single cell suspensions were prepared by forcing the spleens through nylon cell strainers and by suspending the cells in RPMI 1640 medium with $10 \%$ fetal bovine serum. Cells were collected by centrifugation, with blood cells being removed by using red blood cell lysis buffer (Sigma-Aldrich; St Louis, MO, USA).

Flow cytometry analysis. All cells were stained with Ghost Dye-APC/Cy7 (Tonbo biosciences; San Diego, CA, USA) to gate for live cell populations. Splenic cells $\left(1 \times 10^{6}\right)$ were incubated with $0.5 \mu \mathrm{g} / \mathrm{sample}$ anti-mouse CD16/32 antibody (BioLegend; San Diego, CA, USA) for $10 \mathrm{~min}$ on ice to prevent non-specific binding of monoclonal antibodies to the Fc receptors. The surface of the $B$ cells was stained with monoclonal anti-mouse CD19FITC (B-cell surface marker; BioLegend), anti-mouse CD38-PE/Cy7 (memory B-cell marker; BioLegend) and anti-mouse IgG-PE (mature, isotypeswitched B-cell marker; Southern Biotech; Birmingham, AL) for $30 \mathrm{~min}$ in the dark at $4{ }^{\circ} \mathrm{C}$.

To measure $\mathrm{T}$ cell kinetics, splenic cells were pretreated with ionomycin (750 $\mathrm{ng} / \mathrm{ml})$ and phorbol 12- myristate 13-acetate (PMA, $50 \mathrm{ng}$ per sample), and then incubated $2 \mathrm{~h}$ later with Brefeldin $\mathrm{A}(0.7 \mu \mathrm{g}$ per sample) to accumulate intracellular cytokines. The surface of the T cells was stained with monoclonal anti-mouse CD4-PE/Dazzle594 (BioLegend) and antimouse CD8-FITC (BioLegend) for $30 \mathrm{~min}$ in the dark at $4{ }^{\circ} \mathrm{C}$ to distinguish $\mathrm{CD}^{+}$and $\mathrm{CD}^{-}$expressing cells. Stained cells were centrifuged, washed and permeabilized with Foxp3 staining buffer set (eBioscience; San Diego, CA, USA). T cells were stained with anti-mouse IFN- $\gamma$-Percp/Cy5.5 (BioLegend), anti-mouse IL-17A-PE/Cy7 (BioLegend) and anti-mouse Foxp3-PacificBlue (eBioscience) for $30 \mathrm{~min}$ in the dark at $4{ }^{\circ} \mathrm{C}$.

To determine innate immune responses, the surface of DCs was stained with monoclonal anti-mouse CD11c-PE/Dazzle594 (BioLegend), anti-mouse CD11b-Percp/Cy5.5 (BioLegend), anti-mouse CD80-Pacific Blue (BioLegend), anti-mouse CD86-FITC (BioLegend) and anti-mouse MHC-II-PE (Tonbo Biosciences) for $30 \mathrm{~min}$ in the dark at $4{ }^{\circ} \mathrm{C}$.

All stained cells were fixed with $1 \%$ paraformaldehyde in PBS, examined for sterility and then subjected to flow cytometry. Suitable isotype antibodies for all experiments were used as controls. The differential cell population was acquired on flow cytometer (LSRII Fortessa) and analysed using FACS diva software (BD Biosciences, San Jose, CA, USA).

Challenge. On day 120, a set of immunised and PBS-injected control mice ( $n=5$ per group) were exposed by the i.n. route with $1.2 \times 10^{4} \mathrm{CFU} / 40 \mu \mathrm{l}$ $\left(24 \mathrm{LD}_{50}\right)$ of the bioluminescent WT Y. pestis CO92 luc2 strain, which contains the luciferase operon (luc), allowing in vivo imaging of mice for bacterial dissemination in real time. ${ }^{23}$ On days 123 and 130 (day 3 and 10 p.i.), the animals were imaged by using an in vivo imaging system (IVIS) 200 bioluminescent and fluorescence whole-body imaging workstation (Caliper Corp.; Alameda, CA, USA) in the ABSL-3 facility to examine dissemination and progress of infection.

Rat studies. Rats were immunised by the i.m. route with two doses $\left(2 \times 10^{6}\right.$ CFU/100 $\mu \mathrm{l}, 21$ days apart) of the $\Delta / p p \Delta m s b B \Delta$ ail or the $\Delta / p p$ $\triangle m s b B \Delta$ pla mutant. One group of rats received PBS in lieu of bacteria, thus representing a naive, unimmunized control group. Saphenous vein bleeding of all rats occurred on days $0,14,35,56,77$ and 88 . Sera were processed as described above for mice. Total lgG against F1-V in the sera 
(1:5 serially diluted) of all rats was determined as we previously described. ${ }^{23,25}$

On day 42 , spleens were isolated from rats $(n=3$ per group per time point) and were pretreated with ionomycin and PMA and then incubated $2 \mathrm{~h}$ later with Brefeldin A. The surface of the $\mathrm{T}$ cells was stained with monoclonal anti-rat CD4-PE/Cy7 (BioLegend) and anti-rat CD8-APC (BioLegend) for $30 \mathrm{~min}$ in the dark at $4{ }^{\circ} \mathrm{C}$ to distinguish $\mathrm{CD} 4^{+}$and $\mathrm{CD} 8^{-}$ expressing cells. Stained cells were centrifuged, washed and permeabilized with Foxp3 staining buffer set (eBioscience). T cells were stained with antirat IFN- $\gamma$-PE(BioLegend) and anti-rat IL-17A-Percp/Cy5.5 (eBioscience) for $30 \mathrm{~min}$ in the dark at $4^{\circ} \mathrm{C}$. Cells were analysed by Flow Cytometry as described above.

Another set of immunised and PBS-injected control rats ( $n=6$ per group) were exposed by the i.n. route with $1.6-2.3 \times 10^{4} \mathrm{CFU} / 50 \mu \mathrm{l}\left(31-46 \mathrm{LD}_{50}\right)$ on day 43 or day 91 of the WT CO92 luc2 strain. Animals were assessed for morbidity and/or mortality for 2-3 weeks after the exposure. During the second challenge (on day 91), blood and organs (lungs, liver and the spleen) from surviving rats were collected on day 14 post challenge. An aliquot $(200 \mu \mathrm{l})$ of the blood and homogenised organs were plated on the blood agar plates to examine the clearance of the challenge strain from these rats.

\section{Statistical analysis}

For majority of the experiments, one-way analysis of variance (ANOVA) and two-way ANOVA were used with the Tukey's post hoc test for data analysis. We used Kaplan-Meier survival estimates with log-rank (Mantel-Cox) test for animal studies, and $P$ values of $\leqslant 0.05$ were considered significant for all of the statistical tests used.

\section{ACKNOWLEDGEMENTS}

This research was supported by the NIH/NIAID Grant Al064389 awarded to AKC We also acknowledge a UC7 Grant (Al070083), which facilitated our research in the Galveston National Laboratory, UTMB, Galveston, TX, USA. BLT was supported by a predoctoral fellowship from the Jeane B. Kempner Foundation, Galveston, TX, USA and the James W. McLaughlin Endowment Scholar Program, Galveston, TX, USA. JAA was supported in part by the Sealy Center for Vaccine Development, UTMB.

\section{CONTRIBUTIONS}

Bethany $L$ Tiner and Jian Sha planned as well as executed all experiments described above. Bethany $L$ Tiner analysed all collected data and wrote the manuscript. Yingzi Cong and Ashok Chopra helped in the planning of all experiments and discussion of the acquired results. Ashok Chopra and Jian Sha also contributed to the writing and editing of the manuscript. Michelle L Kirtley and Jourdan A Andersson provided help in performing rat studies. Ashok Chopra is the guarantor.

\section{COMPETING INTERESTS}

The authors declare no conflict of interest.

\section{REFERENCES}

1. Bertherat, E. G. Plague around the world, 2010-2015. Wkly. Epidemiol. Rec. 91, 89-104 (2015).

2. Rosenzweig, J. A. et al. Cethromycin-mediated protection against the plague pathogen Yersinia pestis in a rat model of infection and comparison with levofloxacin. Antimicrob. Agents Chemother. 55, 5034-5042 (2011).

3. Layton, R. C. et al. Levofloxacin cures experimental pneumonic plague in African green monkeys. PLoS Negl. Trop. Dis. 5, e959 (2011).

4. Inglesby, T. V. et al. Plague as a biological weapon: medical and public health management. Working Group on civilian biodefense. JAMA 283, 2281-2290 (2000).

5. Smiley, S. T. Current challenges in the development of vaccines for pneumonic plague. Expert Rev. Vaccines 7, 209-221 (2008).

6. Centers for Disease Control and Prevention (CDC). Possession, use, and transfer of select agents and toxins; biennial review: final rule. Fed. Regist. 77, 61083-61115 (2012).

7. Alvarez, M. L. \& Cardineau, G. A. Prevention of bubonic and pneumonic plague using plant-derived vaccines. Biotechnol. Adv. 28, 184-196 (2010),

8. Rosenzweig, J. A. et al. Progress on plague vaccine development. Appl. Microbiol. Biotechnol. 91, 265-286 (2011).
9. Cui, Y. et al. Genetic variations of live attenuated plague vaccine strains (Yersinia pestis EV76 lineage) during laboratory passages in different countries. Infect. Genet. Evol. 26, 172-179 (2014).

10. MMWR. Fatal laboratory-acquired infection with an attenuated Yersinia pestis Strain-Chicago, Illinois, 2009. Morbid. Mortality Wkly. Rep. 60, 201-205 (2011).

11. Quenee, L. E. et al. Hereditary hemochromatosis restores the virulence of plague vaccine strains. J. Infect. Dis. 206, 1050-1058 (2012).

12. Fellows, P. et al. Characterization of a cynomolgus macaque model of pneumonic plague for evaluation of vaccine efficacy. Clin. Vaccine Immunol. 22, 1070-1078 (2015).

13. Agar, S. L. et al. Characterization of the rat pneumonic plague model: infection kinetics following aerosolization of Yersinia pestis CO92. Microbes Infect. 11, 205-214 (2009).

14. Quenee, L. E. et al. Plague in guinea pigs and its prevention by subunit vaccines. Am. J. Pathol. 178, 1689-1700 (2011).

15. Quenee, L. E., Ciletti, N. A., Elli, D., Hermanas, T. M. \& Schneewind, O. Prevention of pneumonic plague in mice, rats, guinea pigs and non-human primates with clinical grade rV10, rV10-2 or F1-V vaccines. Vaccine 29, 6572-6583 (2011).

16. Williamson, E. D. et al. Recombinant $(\mathrm{F} 1+\mathrm{V})$ vaccine protects cynomolgus macaques against pneumonic plague. Vaccine 29, 4771-4777 (2011).

17. Smiley, S. T. Immune defense against pneumonic plague. Immunol. Rev. 225, 256-271 (2008).

18. Food and Drug Administration. African green monkey (Chlorocebus aethiops) animal model development to evaluate treatment of pneumonic plague. Food and Drug Administration, Washington, DC, 2012; http://www.fda.gov/ downloads/AdvisoryCommittees/CommitteesMeetingMaterials/Drugs/Anti-Infec tiveDrugsAdvisoryCommittee/UCM297180.pdf.

19. Sha, J. et al. Characterization of an F1 deletion mutant of Yersinia pestis CO92, pathogenic role of $\mathrm{F} 1$ antigen in bubonic and pneumonic plague, and evaluation of sensitivity and specificity of F1 antigen capture-based dipsticks. J. Clin. Microbiol. 49, 1708-1715 (2011).

20. Quenee, L. E., Cornelius, C. A., Ciletti, N. A., Elli, D. \& Schneewind, O. Yersinia pestis caf1 variants and the limits of plague vaccine protection. Infect. Immun. 76, 2025-2036 (2008).

21. Huang, X. Z., Nikolich, M. P. \& Lindler, L. E. Current trends in plague research: from genomics to virulence. Clin. Med. Res. 4, 189-199 (2006).

22. Perry, R. D. \& Fetherston, J. D. Yersinia pestis-etiologic agent of plague. Clin. Microbiol. Rev. 10, 35-66 (1997).

23. Tiner, B. L. et al. Combinational deletion of three membrane protein-encoding genes highly attenuates Yersinia pestis while retaining immunogenicity in a mouse model of pneumonic plague. Infect. Immun. 83, 1318-1338 (2015)

24. van Lier, C. J. et al. Deletion of Braun lipoprotein and plasminogen-activating protease-encoding genes attenuates Yersinia pestis in mouse models of bubonic and pneumonic plague. Infect. Immun. 82, 2485-2503 (2014).

25. Tiner, B. L. et al. Intramuscular immunization of mice with a live-attenuated triple mutant of Yersinia pestis CO92 induces robust humoral and cell-mediated immunity to completely protect animals against pneumonic plague. Clin. Vaccine Immunol. 22, 1255-1268 (2015).

26. Sha, J. et al. Deletion of the Braun lipoprotein-encoding gene and altering the function of lipopolysaccharide attenuate the plague bacterium. Infect. Immun. 81, 815-828 (2013).

27. Glauser, M. P., Zanetti, G., Baumgartner, J. D. \& Cohen, J. Septic shock: pathogenesis. Lancet 338, 732-736 (1991).

28. Braun, V. \& Hantke, K. Biochemistry of bacterial cell envelopes. Annu. Rev. Biochem. 43, 89-121 (1974).

29. Neilsen, P. O., Zimmerman, G. A. \& Mclntyre, T. M. Escherichia coli Braun lipoprotein induces a lipopolysaccharide-like endotoxic response from primary human endothelial cells. J. Immunol. 167, 5231-5239 (2001).

30. Aliprantis, A. O. et al. Cell activation and apoptosis by bacterial lipoproteins through toll-like receptor-2. Science 285, 736-739 (1999).

31. Clementz, T., Bednarski, J. J. \& Raetz, C. R. Function of the htrB high temperature requirement gene of Escherchia coli in the acylation of lipid A: HtrB catalyzed incorporation of laurate. J. Biol. Chem. 271, 12095-12102 (1996).

32. Clementz, T., Zhou, Z. \& Raetz, C. R. Function of the Escherichia coli msbB gene, a multicopy suppressor of htrB knockouts, in the acylation of lipid A. Acylation by MsbB follows laurate incorporation by HtrB. J. Biol. Chem. 272 10353-10360 (1997).

33. Anisimov, A. P. et al. Effect of deletion of the IpxM gene on virulence and vaccine potential of Yersinia pestis in mice. J. Med. Microbiol. 56, 443-453 (2007).

34. Oyston, P. C. et al. Expression of heterologous O-antigen in Yersinia pestis KIM does not affect virulence by the intravenous route. J. Med. Microbiol. 52, 289-294 (2003).

35. Perez-Gutierrez, C., Llobet, E., Llompart, C. M., Reines, M. \& Bengoechea, J. A. Role of lipid A acylation in Yersinia enterocolitica virulence. Infect. Immun. 78, 2768-2781 (2010). 
36. Bartra, S. S. et al. Resistance of Yersinia pestis to complement-dependent killing is mediated by the Ail outer membrane protein. Infect. Immun. 76, 612-622 (2008).

37. Felek, S. \& Krukonis, E. S. The Yersinia pestis Ail protein mediates binding and Yop delivery to host cells required for plague virulence. Infect. Immun. 77, 825-836 (2009).

38. Felek, S., Tsang, T. M. \& Krukonis, E. S. Three Yersinia pestis adhesins facilitate Yop delivery to eukaryotic cells and contribute to plague virulence. Infect. Immun. 78, 4134-4150 (2010)

39. Hinnebusch, B. J. et al. Role of the Yersinia pestis Ail protein in preventing a protective polymorphonuclear leukocyte response during bubonic plague. Infect. Immun. 79, 4984-4989 (2011).

40. Kolodziejek, A. M. et al. Phenotypic characterization of OmpX, an Ail homologue of Yersinia pestis KIM. Microbiology 153, 2941-2951 (2007).

41. Kolodziejek, A. M. et al. Outer membrane protein X (Ail) contributes to Yersinia pestis virulence in pneumonic plague and its activity is dependent on the lipopolysaccharide core length. Infect. Immun. 78, 5233-5243 (2010).

42. Tsang, T. M., Felek, S. \& Krukonis, E. S. Ail binding to fibronectin facilitates Yersinia pestis binding to host cells and Yop delivery. Infect. Immun. 78, 3358-3368 (2010).

43. Yamashita, S. et al. Structural insights into Ail-mediated adhesion in Yersinia pestis. Structure. 19, 1672-1682 (2011).

44. van Lier, C. J. et al. Further characterization of a highly attenuated Yersinia pestis CO92 mutant deleted for the genes encoding Braun lipoprotein and plasminogen activator protease in murine alveolar and primary human macrophages. Microb. Pathog. 80C, 27-38 (2015).

45. Erova, T. E. et al. Evaluation of protective potential of Yersinia pestis outer membrane protein antigens as possible candidates for a new-generation recombinant plague vaccine. Clin. Vaccine Immunol. 20, 227-238 (2013).

46. Feodorova, V. A. et al. Pleiotropic effects of the IpxM mutation in Yersinia pestis resulting in modification of the biosynthesis of major immunoreactive antigens. Vaccine 27, 2240-2250 (2009).

47. Clements, J. D. \& Freytag, L. C. Parenteral vaccination can be an effective means of inducing protective mucosal responses. Clin. Vaccine Immunol. 23, 438-441 (2016).

48. Sha, J. et al. A non-invasive in vivo imaging system to study dissemination of bioluminescent Yersinia pestis CO92 in a mouse model of pneumonic plague. Microb. Pathog. 55, 39-50 (2013).

49. Zhang, X. et al. Kinetics of memory B cell and plasma cell responses in the mice immunized with plaque vaccines. Scand. J. Immunol. 79, 157-162 (2014).

50. Anderson, S. M., Tomayko, M. M., Ahuja, A., Haberman, A. M. \& Shlomchik, M. J. New markers for murine memory $B$ cells that define mutated and unmutated subsets. J. Exp. Med. 204, 2103-2114 (2007).
51. Xiao, Y., Hendriks, J., Langerak, P., Jacobs, H. \& Borst, J. CD27 is acquired by primed $\mathrm{B}$ cells at the centroblast stage and promotes germinal center formation. J. Immunol. 172, 7432-7441 (2004).

52. Sanz, I., Wei, C., Lee, F. E. \& Anolik, J. Phenotypic and functional heterogeneity of human memory B cells. Semin. Immunol. 20, 67-82 (2008).

53. Ridderstad, A. \& Tarlinton, D. M. Kinetics of establishing the memory B cell population as revealed by CD38 expression. J. Immunol. 160, 4688-4695 (1998).

54. Nduati, E. W. et al. HIV-exposed uninfected infants show robust memory B cell responses in spite of a delayed accumulation of memory B cells: An observational study in the first two years of life. Clin. Vaccine Immunol. 23, 576-585 (2016).

55. Wang, Z. et al. Long-term observation of subunit vaccine F1-rV270 against Yersinia pestis in mice. Clin. Vaccine Immunol. 17, 199-201 (2010).

56. Hume, D. A. The many alternative faces of macrophage activation. Front. Immunol. 6, 370 (2015).

57. Lin, J. S. et al. TNFa and IFNy contribute to F1/LcrV-targeted immune defense in mouse models of fully virulent pneumonic plague. Vaccine 29, 357-362 (2010).

58. Kumar, P., Chen, K. \& Kolls, J. K. Th17 cell based vaccines in mucosal immunity. Curr. Opin. Immunol. 25, 373-380 (2013).

59. Lin, J. S., Kummer, L. W., Szaba, F. M. \& Smiley, S. T. IL-17 contributes to cell-mediated defense against pulmonary Yersinia pestis infection. J. Immunol. 186, 1675-1684 (2011).

60. Szaba, F. M. et al. D27-pLpxL, an avirulent strain of Yersinia pestis, primes T cells that protect against pneumonic plague. Infect. Immun. 77, 4295-4304 (2009)

61. Moore-Connors, J. M., Fraser, R., Halperin, S. A. \& Wang, J. CD4 ${ }^{+}$CD25 $5^{+}$Foxp3 $3^{+}$ regulatory $T$ cells promote Th17 responses and genital tract inflammation upon intracellular Chlamydia muridarum infection. J. Immunol. 191, 3430-3439 (2013).

62. Wang, Z. et al. Regulatory T cells promote a protective Th17-associated immune response to intestinal bacterial infection with C. rodentium. Mucosal Immunol. 7, 1290-1301 (2014)

63. Kambayashi, T. \& Laufer, T. M. Atypical MHC class Il-expressing antigen-presenting cells: can anything replace a dendritic cell? Nat. Rev. Immunol. 14, 719-730 (2014).

(c) (i)

This work is licensed under a Creative Commons Attribution 4.0 International License. The images or other third party material in this article are included in the article's Creative Commons license, unless indicated otherwise in the credit line; if the material is not included under the Creative Commons license, users will need to obtain permission from the license holder to reproduce the material. To view a copy of this license, visit http://creativecommons.org/licenses/ by/4.0/

(c) The Author(s) 2016 